\title{
In Sickness and in Health: Perineuronal Nets and Synaptic Plasticity in Psychiatric Disorders
}

\author{
Harry Pantazopoulos ${ }^{1,2}$ and Sabina Berretta ${ }^{1,2,3}$ \\ ${ }^{1}$ Translational Neuroscience Laboratory, Mclean Hospital, Belmont, MA 02478, USA \\ ${ }^{2}$ Department of Psychiatry, Harvard Medical School, Boston, MA 02215, USA \\ ${ }^{3}$ Program in Neuroscience, Harvard Medical School, Boston, MA 02215, USA \\ Correspondence should be addressed to Sabina Berretta; s.berretta@mclean.harvard.edu
}

Received 21 July 2015; Accepted 27 September 2015

Academic Editor: Daniela Carulli

Copyright (C) 2016 H. Pantazopoulos and S. Berretta. This is an open access article distributed under the Creative Commons Attribution License, which permits unrestricted use, distribution, and reproduction in any medium, provided the original work is properly cited.

\begin{abstract}
Rapidly emerging evidence implicates perineuronal nets (PNNs) and extracellular matrix (ECM) molecules that compose or interact with PNNs, in the pathophysiology of several psychiatric disorders. Studies on schizophrenia, autism spectrum disorders, mood disorders, Alzheimer's disease, and epilepsy point to the involvement of ECM molecules such as chondroitin sulfate proteoglycans, Reelin, and matrix metalloproteases, as well as their cell surface receptors. In many of these disorders, PNN abnormalities have also been reported. In the context of the "quadripartite" synapse concept, that is, the functional unit composed of the pre- and postsynaptic terminals, glial processes, and ECM, and of the role that PNNs and ECM molecules play in regulating synaptic functions and plasticity, these findings resonate with one of the most well-replicated aspects of the pathology of psychiatric disorders, that is, synaptic abnormalities. Here we review the evidence for PNN/ECM-related pathology in these disorders, with particular emphasis on schizophrenia, and discuss the hypothesis that such pathology may significantly contribute to synaptic dysfunction.
\end{abstract}

\section{Introduction}

The classic view of psychiatric disorders as "neuronal" disorders has been challenged in recent years by rapidly emerging evidence pointing to the involvement of the extracellular matrix (ECM), glial cells, and their interactions [18]. This evidence represents a significant departure from mainstream views and is driving the field toward a growing understanding of these elements as closely interacting components of functional units, such as the "tetrapartite synapse." This latter term, originally proposed by Dityatev et al. [9], aptly describes the functional unit composed of the of pre- and postsynaptic terminals, astroglial processes, and synaptic/perisynaptic ECM complexes [10-14]. Here, we review evidence for the involvement of the ECM in psychiatric disorders and focus on the hypothesis that ECM abnormalities may contribute to a critical pathological component shared by a large subgroup of these disorders, that is, disruption of synaptic functions [15-21]. First, evidence for
ECM abnormalities in schizophrenia, the main focus of these authors' studies, is discussed, with particular emphasis on loss of perineuronal nets (PNNs) in several brain regions in this disorder. We then briefly review evidence for a significant involvement of synaptic pathology in this disorder and follow with a discussion on the potential mechanisms linking such pathology to ECM/PNN abnormalities. Finally, evidence for ECM involvement in other psychiatric disorders is reviewed, with reference to molecular families known to play a role in synaptic functions. The specific patterns and causes of ECM abnormalities in each of these disorders are not yet well understood and may be disorder-specific. We postulate that overlapping patterns of ECM/PNN abnormalities may underlie shared synaptic pathology in these disorders.

It should be emphasized here that synaptic regulation is only one of several critical functions performed by the ECM during pre- and postnatal brain development as well as adulthood (for reviews see [22-30]). Thus, in addition to synaptic dysregulation, the consequences of brain ECM abnormalities 
may be complex and far-reaching, spanning from disruption of axonal guidance, neuronal differentiation, and migration in early brain development to circuit consolidation and closure of critical periods in postnatal development and finally axonal signal conduction and regulation of the blood/brain barrier in the adult brain $[1,2,31-38]$.

\section{Schizophrenia}

2.1. ECM/PNN Abnormalities in Schizophrenia. Schizophrenia is a chronic, severe, and disabling brain disorder characterized by psychotic symptoms and disruptions of normal emotions and behaviors. Growing evidence points to ECM abnormalities as a component of the core pathophysiology of schizophrenia. Converging results from human genetic and postmortem studies show genetic vulnerabilities for genes encoding several key ECM molecules, including chondroitin sulfate proteoglycans (CSPGs), Reelin, semaphorin 3A, integrins, and remodeling enzymes, as well as dysregulated expression of these molecules in glial cells, and disruption of organized ECM structures such as PNNs (see references below). Animal models indicate that these abnormalities may have far-reaching consequences on neural circuits involved in schizophrenia [39-41]. These findings are briefly reviewed below.

2.1.1. CSPGs. In subjects with schizophrenia, we first reported marked decreases of CSPG-labeled PNNs in the amygdala and entorhinal cortex [42], interconnected brain regions involved in emotion-related learning and associative sensory information processing and in the pathophysiology of schizophrenia [43-47]. In this study, PNNs were detected using the lectin wisteria floribunda agglutinin (WFA; Figure 1), which labels PNNs predominantly associated with GABAergic neurons expressing the calcium binding protein parvalbumin (PVB) [48-54]. Consistently, lower numbers of WFA-labeled PNNs were observed in the lateral nucleus of the amygdala and the superficial layers of the entorhinal cortex, where these interneurons are primarily located [42]. A similar distribution pattern of PNN decreases was detected using antibodies against aggrecan, one of the main CSPGs in the brain [55]. In contrast, immunolabeling with antibodies raised against a specific chondroitin sulfate 6 (CS-6; Figure 1) pattern revealed more extensive PNN distribution in the normal human amygdala and decreases in subjects with schizophrenia, including not only the lateral nucleus but also the basal, accessory basal, cortical, and medial amygdala nuclei [55] (Figure 2). PNN reduction in this latter nucleus is of particular interest, as it suggests that GABAergic projection neurons are also affected by PNN abnormalities. Notably, PNN decreases were not accompanied by neuron number reductions $[42,43]$, pointing to actual loss, or altered neurochemical composition, of PNNs. Lower densities of WFA-labeled PNNs were also detected in layers III and V of the prefrontal cortex of subjects with schizophrenia [56]. Interestingly, the visual cortex did not show similar changes [56], suggesting that while being widespread PNN decreases may spare brain regions that are not heavily involved in the pathology of schizophrenia.

In addition to CSPG-labeled PNN decreases, markedly altered CSPG expression in schizophrenia was also detected in glial cells and "glial clusters" in the amygdala, as well as in olfactory receptor neurons in the olfactory epithelium $[42,55,57]$. In parallel to PNN-related findings, these changes did not appear to depend on altered cell numbers and did not depend on disease-related confounding factors such as exposure to pharmacological treatment, substance abuse, onset and duration of the illness, and so forth, further supporting the idea that altered CSPG expression in schizophrenia may represent a core feature of this disorder $[42,55,57]$.

Further support for CSPG involvement in schizophrenia comes from molecular dissection of the neuregulinErbB4 pathway, which revealed an association with a genetic polymorphism in PTPRZ1, the gene encoding for receptor phosphotyrosine phosphatase beta/zeta (RPTPbeta) with schizophrenia [58]. RPTPbeta is a transmembrane CSPG shown to play a role in synaptic plasticity and learning [59-63]. Increased mRNA expression of PTPRZ1 has been reported in the amygdala and prefrontal cortex of subjects with schizophrenia $[39,42]$. Genetic studies have further identified associations of schizophrenia with the genes encoding for the CSPGs neurocan (NCAN) and neuroglycanC $[64,65]$, suggesting that abnormal CSPG expression in schizophrenia may be due, at least in part, to genetic factors.

2.1.2. Reelin. The glycoprotein Reelin is arguably one of the ECM molecules most extensively investigated in schizophrenia and other psychiatric disorders. In subjects with schizophrenia, it has been widely reported to be decreased in a number of cortical areas [66-70]. Several studies have shown that Reelin expression is reduced concurrently with GAD67, one of the main synthetic enzymes for GABA, in cortical GABAergic interneurons, and that these changes may be the consequence of an epigenetic hypermethylation of RELN and GAD67 promoters in these interneurons [70-74]. Notably, Reelin expression was found to be decreased in interstitial white matter neurons, in a study that also confirmed increased density of these neurons in schizophrenia $[75,76]$. Together, these studies elegantly link a disruption of Reelin expression in GABAergic neurons to dendritic spine loss and altered neuronal migration in schizophrenia.

2.1.3. Semaphorins. Members of the semaphorin family, and semaphorin $3 \mathrm{a}$ in particular, have also been shown to be altered in schizophrenia, potentially in conjunction with Reelin $[66,77]$. In particular, increased semaphorin 3A and decreased Reelin expression were detected in the cerebellum of subjects with schizophrenia, while altered expression of multiple members of the semaphorin family was observed in the prefrontal cortex [66]. Genetic polymorphisms of genes encoding for semaphorin $3 \mathrm{D}$ and semaphorin receptor plexin A2 have also been associated with schizophrenia $([78,79]$, but see also [80]). 


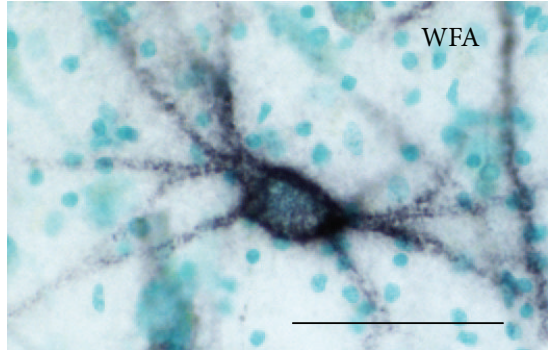

(a)

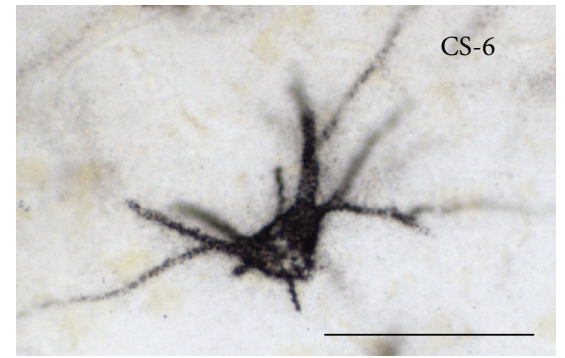

(b)

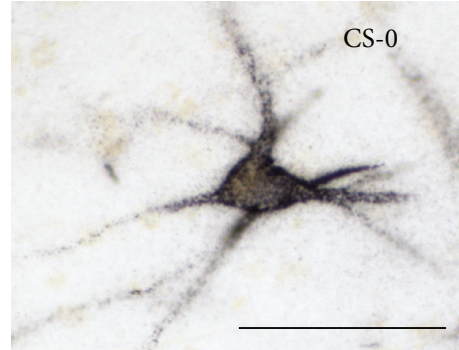

(c)

FIGURE 1: PNNs in the human amygdala. (a) PNN labeled with wisteria floribunda agglutinin (WFA) lectin, which binds to N-acetylgalactosamine on the terminal end of chondroitin sulfate chains. (b) PNN immunolabeled using the mAB antibody 3B3 against native chondroitin sulfate motifs specific for chondroitin-6-sulfate (CS-6). 3B3-immunolabeled PNNs are more numerous and show a much broader distribution in the human amygdala with respect to those labeled with WFA. (c) PNN immunolabeled with mAB antibody 1B5, raised against nonsulfated chondroitin sulfate (CS-0) (3B3 and 1B5 are a generous gift from Dr. Bruce Caterson, University of Cardiff, UK). Scale bar $=$ $50 \mu \mathrm{m}$.

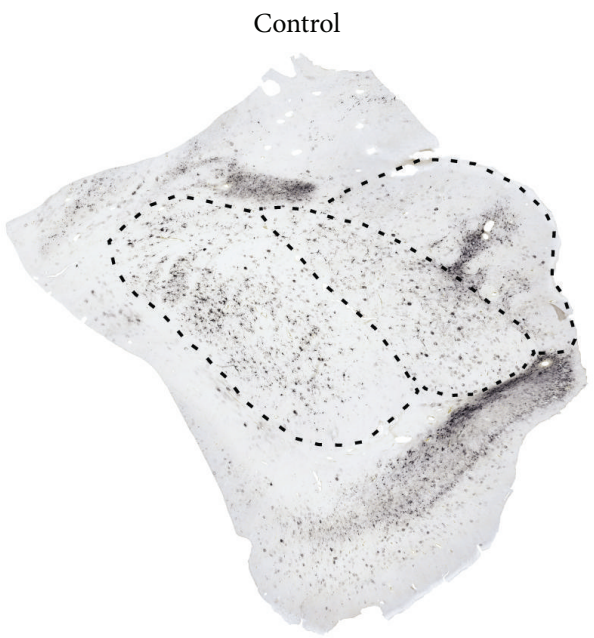

(a)

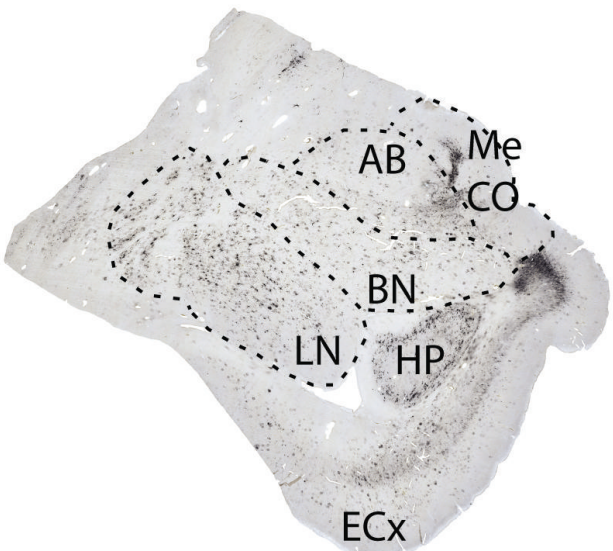

(b)
Schizophrenia

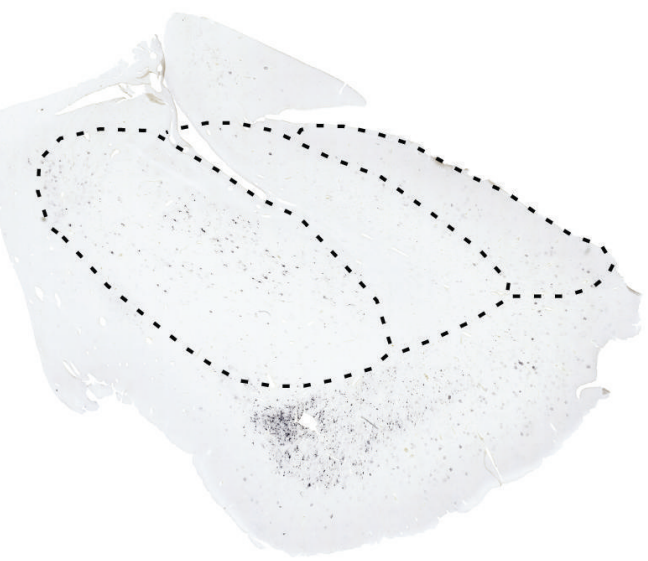

(c)

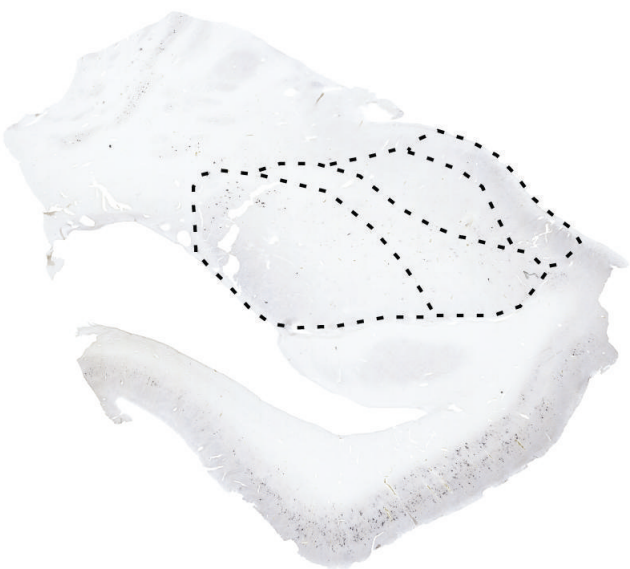

(d)

FIGURE 2: Decreased CS-6 in the amygdala of subjects with schizophrenia. In the amygdala of control subjects, CS-6(3B3)-labeled PNNs and glial cell clusters are distributed in the lateral (LN), basal (BN), accessory basal (AB), and corticomedial (CO-Me) nuclei (a, b). In subjects with schizophrenia, marked decreases of PNNs and glia cell clusters immunolabeled for CS-6(3B3) were observed in the amygdala of (c, d) [55]. ECx: entorhinal cortex. HP: hippocampus. 
2.1.4. Integrins. Integrins, a family of heterodimeric cell adhesion molecules (CAMs) consisting of several different $\alpha$ - and $\beta$-subunits, interact with ECM molecules to carry out a multitude of developmental and adult brain functions. Support for the idea that integrins may be implicated in the pathology of schizophrenia comes in part from genetic studies pointing to association of this disorder with a number of integrin gene variants, such as SNPs in the ITGA8 and ITGB3 genes [81, 82]. Additional evidence supporting the involvement of integrins in schizophrenia includes increased expression of integrin $\alpha$ (IIb) and $\beta$ (IIIa) in first episode subjects with schizophrenia and, notably, abnormal cell adhesion in cultures from olfactory mucosa biopsies from patients with this disorder, which was ameliorated by antibodies blocking integrins $[83,84]$.

2.1.5. Matrix Metalloproteases. Proteolytic ECM remodeling, shown to play a key role in synaptic plasticity, is mediated by matrix metalloproteases (MMPs), "a disintegrin and metalloproteases" (ADAMs), and "a disintegrin and metalloproteases with a thrombospondin motif" (ADAMTS), through their substrates, such as CAMs, CSPGs, and ECM receptors [85-89]. Several of these enzymes have been implicated in the pathophysiology of schizophrenia. Elevated levels of MMP9, and "tissue inhibitor of metalloproteinases 1" (TIMP-1) which blocks MMP-9 activity, were reported in blood samples from subjects with this disorder [90, 91]. Increased MMP-9 blood serum levels were also identified in treatment resistant patients [92]. A recent gene expression profiling study of the superior temporal gyrus showed altered mRNA expression of MMPs and ADAMTSs in schizophrenia, including MMP16 [93]. The possibility that genetic vulnerability may contribute to altered expression of matrix metalloproteases in schizophrenia is supported by converging results from several recent genetic association and genome-wide association studies showing that gene variants encoding for a number of these enzymes, including ADAMTSL3, ADAMTS12, ADAMTS16, ADAM22, and MMP-16, may be associated with this disorder [94-98].

\subsubsection{Evidence for ECM Abnormalities from Animal Model} Studies. Consistent with human studies, animal models provide evidence that abnormalities affecting the ECM, and CSPGs in particular, may contribute to the pathophysiology of schizophrenia. Transgenic mice overexpressing PTPRZ1 show numerous anatomical and behavioral abnormalities also observed in this disorder, including delayed oligodendrocyte maturation, working memory deficits, and altered glutamatergic, dopaminergic, and GABAergic activity [39]. Experimentally induced enzymatic PNN digestion in the mouse hippocampus mimics several functional abnormalities, including increased activity of dopamine neurons in the ventral tegmental area, which is suspected to occur in schizophrenia [40]. Finally, a rodent model for oxidative stress in schizophrenia showed that PNNs protect neurons expressing PVB from oxidative stress, while at the same time they are vulnerable to it [41]. Thus, loss of PNNs may render these neurons more susceptible to the excitotoxic effects of oxidative stress believed to occur in schizophrenia [99-101].

2.2. Synaptic Pathology in Schizophrenia. Solid and growing evidence shows that disruption of synaptic functions represents a core component of the pathology of schizophrenia. Altered synaptic transmission of key CNS neurotransmitters, including glutamate and GABA, altered expression of synaptic molecules, and loss of dendritic spines have been consistently observed in schizophrenia [16, 102-111]. These interlinked components are briefly reviewed below and placed in the context of ECM/PNN abnormalities.

2.2.1. Glutamatergic Synaptic Signaling and GABAergic Inhibitory Neurons. Several neurotransmitter systems have been implicated in the pathophysiology of schizophrenia. For the purpose of this review, we focus on the involvement of glutamatergic transmission and GABAergic inhibitory neurons in schizophrenia and discuss the potential contribution of ECM/PNN pathology to abnormalities affecting these systems. Importantly, abnormalities affecting these neurotransmitters are closely linked to one another. For instance, GABAergic interneurons powerfully regulate intrinsic information processing and glutamatergic efferents (e.g., [112115]). Conversely, these interneurons are particularly sensitive to glutamate NMDA receptor hypofunction $[116,117]$.

Abnormalities affecting the GABAergic system have been consistently reported in several brain regions in schizophrenia $[115,118-129]$. These include decreases of inhibitory neurons, loss of GABAergic terminals, and expression of glutamatergic receptors on distinct populations of GABAergic interneurons [115, 130, 131]. The regulation of glutamatergic inputs to these neurons, and PVB-positive neurons in particular, has been a specific focus of attention in schizophrenia, as these inputs play a key role in controlling synchronous oscillations at gamma band frequencies, known to be affected in schizophrenia, and are critical to information processing in cortical circuits involved in this disorder [122, 126, 132, 133].

Altered expression of NMDA and, perhaps to a lesser extent, AMPA receptor proteins has been reported in subjects with schizophrenia, pointing to a disruption of synaptic glutamate signaling networks in this disorder [134-142]. In addition, and perhaps more consistently, the expression of a large number of glutamate receptor accessory proteins, including proteins associated with the postsynaptic density, is altered in several brain regions in people with schizophrenia (for review see [141]). Converging evidence from postmortem, genetic, and animal models also points to abnormal expression of the NMDA receptor coagonists, D-serine and glycine, and the endogenous glycine modulatory site antagonist kynurenic acid [143-150]. This well-replicated finding resonates with intriguing evidence for ECM-mediated modulation of the NMDA receptor glycine site [151].

2.3. Potential Contribution of ECM Abnormalities to Synaptic Glutamatergic Transmission on GABAergic Neurons. PNNs tightly surround synaptic contacts on the somata, dendrites, and proximal axon segment of distinct populations 


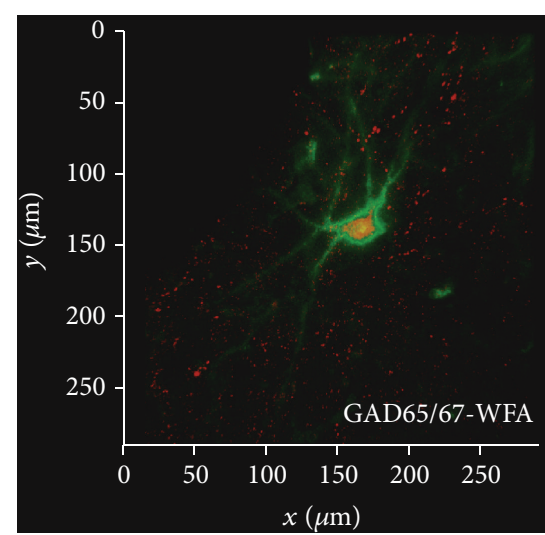

(a)

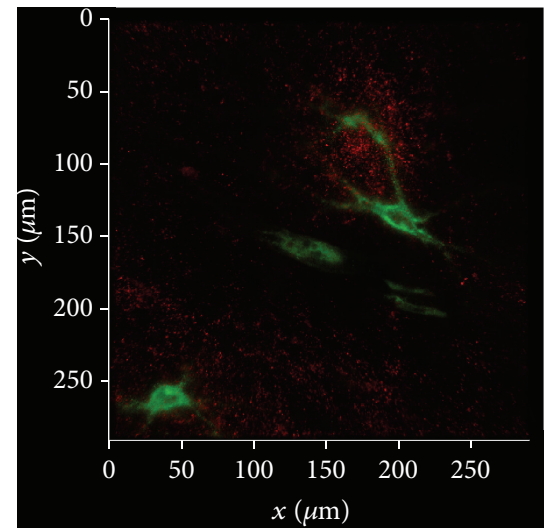

(d)

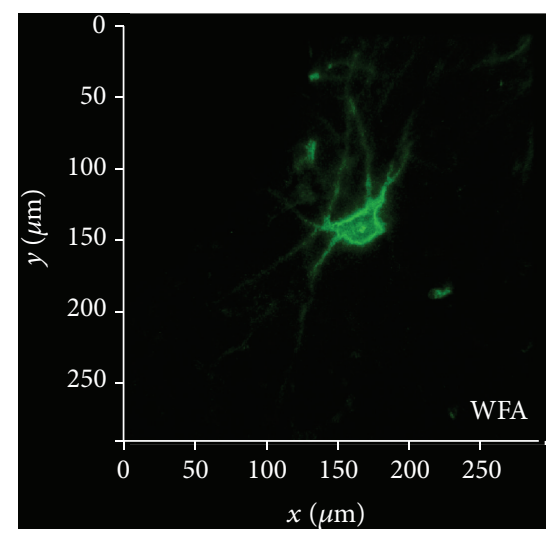

(b)

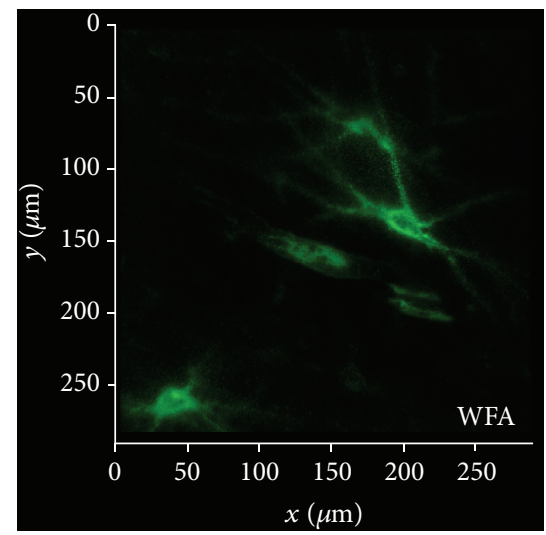

(e)

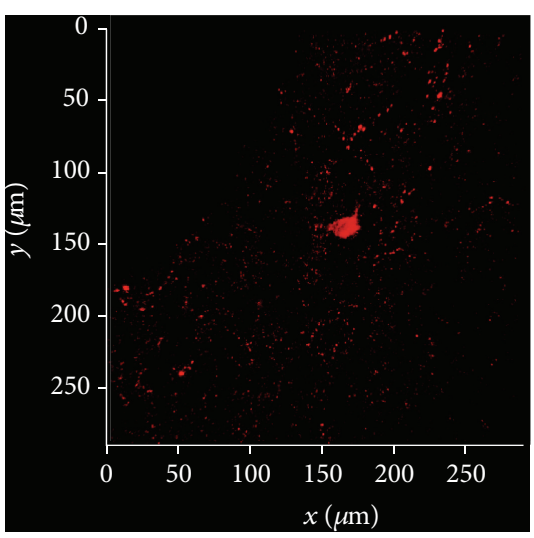

(c)

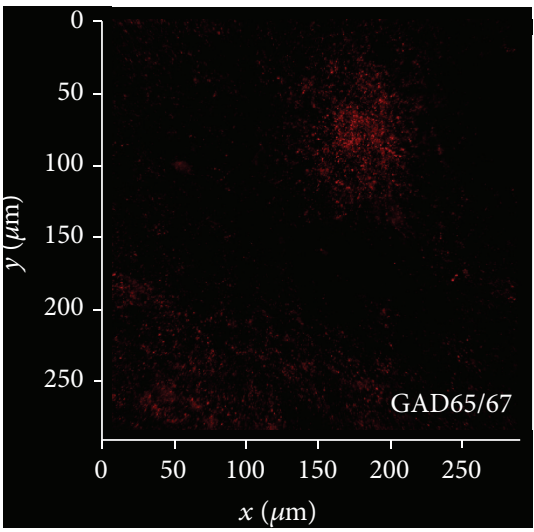

(f)

FIGURE 3: PNNs are associated with heterogeneous neuronal populations. Confocal micrographs depicting WFA-labeled PNNs surrounding GABAergic neurons expressing GAD65/67 in the healthy human amygdala (a-c). Consistently, WFA-labeled PNNs have been shown to be typically associated with neurons expressing parvalbumin. However, we have previously reported that a small subpopulation of these PNNs ensheathes parvalbumin-negative neurons [152]. Preliminary findings shown in (d)-(f) suggest that these neurons do not express GAD65/67 and may therefore correspond to excitatory neurons.

of neurons. These consist of several GABAergic interneuron populations, including, but not limited to, those expressing PVB or somatostatin, and GABAergic projection neurons such as those in the reticular nucleus of the thalamus, the central nucleus of the amygdala, and Purkinje cells in the cerebellum [2, 48, 153-158]. A subset of excitatory corticocortical pyramidal cells and spinal cord motor neurons have also been found to bear PNNs [159]. It is likely that the range of neuronal populations associated with PNNs has not yet been fully accounted for, particularly as the molecular and structural heterogeneity of these ECM structures is still not well understood. For instance, in the human amygdala, a small population of WFA-labeled PNNs ensheathes neurons lacking expression of glutamic acid decarboxylase (GAD) and thus likely represented excitatory neurons (unpublished results; Figure 3 ). In addition, we recently reported that PNNs labeled with an antibody (3B3) targeting a native chondroitin6 -sulfate motif are far more numerous and widely distributed than those labeled with the lectin wisteria floribunda agglutinin (WFA) and well represented in amygdalar nuclei virtually devoid of PVB-positive neurons [55]. Therefore, abnormalities affecting PNNs may potentially impact a broad variety of inhibitory, as well as excitatory, neuronal populations. Converging evidence suggests that, in schizophrenia, $\mathrm{ECM} / \mathrm{PNN}$ components known to regulate glutamatergic and GABAergic inputs on GABAergic neurons are abnormal, potentially contributing to intrinsic information processing and activity outflow.

2.4. Regulation of Glutamatergic and GABA Synapses by PNNs and Perisynaptic ECM Condensations. Growing evidence points to a key role played by PNNs in synaptic regulation, particularly of glutamatergic synapses (for extensive reviews see $[11,12,38,160,161])$. In particular, ECM/PNNs affect the diffusion of glutamate receptors laterally within the plasma membrane, as well as receptor clustering within the synapse, thus controlling a fundamental mechanism of synaptic regulation and plasticity $[162,163]$. It is thought that this key PNN function may be accomplished by a combination of passive and active mechanisms $[160,162]$. Although less is currently known with regard to PNN regulation of GABAergic inputs, a recent study reported that PNN enzymatic 
digestion increases the number of inhibitory synapses on PVB-positive interneurons [164]. We briefly describe below some examples according to their potential relevance to schizophrenia. We suggest that, in schizophrenia, concurrent disruption of CSPG expression and molecular families interacting with PNN components may contribute synergistically to glutamatergic synapse dysregulation on neurons associated with PNNs.

2.4.1. PNNs as a Passive Barrier. Highly viscous CSPGs, and other ECM/PNN components, form an effective passive diffusion barrier, controlling the lateral diffusion exchanges of AMPA receptors between the synaptic and extrasynaptic compartments [162]. By restricting the lateral diffusion of AMPA receptors from the extrasynaptic space to the synapse, PNNs allow synaptic desensitization during high frequency firing $[160,162,165]$. Consistent with this function, PNN enzymatic digestion results in increased excitability of interneurons [166]. In pathological states, such as schizophrenia, PNN disruption may result in unregulated lateral membrane diffusion of AMPA receptors, thus impacting excitatory synaptic activation and resembling a more "juvenile" state of synaptic regulation.

2.4.2. Chondroitin Sulfate Proteoglycans. CSPGs are key contributors to the composition of PNNs [167-169] and are also found in other structures described as perisynaptic coats [154, 170-174]. An increasing number of studies show that these molecules are critically involved in the regulation of synaptic plasticity. For example, electrophysiological recordings from in vitro mouse hippocampal slices treated with chABC to remove CSPGs show a twofold decrease in long term potentiation (LTP) but not in short term plasticity [175]. A similar decrease of LTP was also observed in mice lacking a key PNN component, tenascin-R, suggesting that CSPG regulation of long term synaptic plasticity occurs through modulation of PNN composition [175].

Studies focused on specific CSPG molecules and CSsulfation reveal a complex role in developmental and adult regulation of synaptic plasticity. For example, overexpression of CS-6 sulfation in mice leads to failure to instate an adult form of restricted plasticity, resulting in abnormally persistent synaptic plasticity and reduced PNN formation [176]. In the cortex and hippocampus, expression of the CSPG PTPRZ1 was found to be associated with synaptic remodeling [59-62]. Knockout of PTPRZ1 in mice results in enhanced LTP and deficits in spatial learning exclusively in adults [63]. In contrast, mice overexpressing PTPRZ1 show hippocampal LTP deficits, as well as a number of molecular, anatomical, and behavioral abnormalities reminiscent of those observed in subjects with schizophrenia [39]. Together with the increased expression of PTPRZ1 in subjects with this disorder $[39,42]$, these findings are consistent with the possibility that increased PTPRZ1 expression may contribute to deficits in synaptic plasticity in schizophrenia. Other CSPGs have also been shown to regulate plasticity. Adult mice deficient for the CSPG brevican display deficits in hippocampal early stage LTP and decreased PNN formation
[177], whereas mice deficient for neurocan display decreased late stage LTP but normal PNN formation [178]. Further evidence comes from studies showing that brevican and versican are increased in the hippocampus of rats during memory retrieval in the Morris water maze spatial memory task [179]. Overall, altered expression of CSPGs and CSsulfation patterns have the potential to contribute to disregulated synaptic plasticity in psychiatric disorders during developmental stages, particularly during critical periods of plasticity, as well as adult regulation of synaptic plasticity.

2.4.3. Reelin. Perhaps one of the most well-replicated findings in the pathophysiology of schizophrenia and, incidentally, autism is a disruption of Reelin expression [66-74, 76]. In the adult brain, Reelin is secreted in the ECM by subpopulations of GABAergic interneurons and takes part in the composition of at least a subpopulation of PNNs [180-182]. Reelin's effects are mediated through its main lipoprotein receptors, apolipoprotein E receptor 2 (ApoER2) and very-low-density lipoprotein receptor (VLDLR) [183, 184], as well as through the CAMs of the integrin family and the Src family kinases [184-188]. Accumulating evidence shows that secreted Reelin powerfully enhances LTP and glutamatergic synaptic transmission by regulating NMDA and AMPA receptors $[187,188]$. For instance, Reelin regulates the composition of NMDA receptors, controlling the predominance and/or phosphorylation of the NR2 NMDA receptor subunits, and enhances AMPA responses by increasing the number of AMPA receptors on the postsynaptic membrane $[180,188]$.

2.4.4. Integrins. Interactions between integrins and ECM/ PNN components, including Reelin, thrombospondins, fibrinogen, and others, have been shown to regulate synaptic glutamatergic transmission [160]. Notably, integrin signaling is bidirectional; that is, it can activate intracellular signaling pathways in response to changes in the extracellular environment and impact on cell adhesion in response to intracellular signaling [189]. This may allow integrins to play complex roles in synaptic plasticity, including carrying out structural and functional changes that accompany LTP [189-191]. IntegrinECM interactions have been shown to regulate AMPA receptor internalization, surface mobility of NMDA receptor subunits, and synaptic dwell time of glycine receptors and their scaffolding molecule gephyrin $[151,192,193]$.

2.4.5. Neuronal Activity-Regulated Pentraxin. An intriguing example of interactions between ECM molecules and factors regulating synaptic plasticity is represented by the "neuronal activity-regulated pentraxin" (NARP). NARP is an immediate early gene in which its protein product is secreted in an activity-dependent manner by excitatory terminals onto GABAergic PVB-positive neurons, where it promotes clustering of AMPA receptor subunits $[194,195]$. This mechanism regulates homeostatic scaling of excitatory inputs so that increased network activity strengthens the excitatory inputs on PVB-positive interneurons, in turn powerfully inhibiting 
excitatory projection neurons [195]. PNNs ensheathing PVBpositive neurons are critical to the maintenance of high levels of NARP at excitatory synapses on these neurons [195]. CSPG enzymatic digestion markedly decreased NARP at excitatory synapses on PVB-positive neurons without decreasing the overall NARP expression [195]. In subjects with schizophrenia, marked Narp mRNA decreases were reported in the prefrontal cortex [196], a brain region where PNN decreases were also detected [56]. Although a causal relationship between these two findings has not been established thus far, it is reasonable to postulate that, in conjunction, NARP and PNN decreases may synergistically impact glutamatergic synapses on PVB-positive neurons in schizophrenia.

2.4.6. Matrix Metalloproteases. Secreted extracellular matrix proteases, such as "tissue plasminogen activator" (tPA) and MMPs, affect excitatory transmission. For instance, tPA has been found to play a role in LTP through several mechanisms, including cleavage of the NR1 subunit of the NMDA receptor, resulting in potentiation of NMDA current, and cleavage of proBDNF resulting in availability of mature BDNF [197200]. Altered levels of tPA have been reported in subjects with schizophrenia [201-203]. Although it is not currently known whether these abnormalities are linked to comorbidities, such as alcoholism, inflammatory, and autoimmune disorders, or metabolic disorders [201-203], these findings support the intriguing possibility that $\mathrm{PAA}$ abnormalities may contribute to a disruption of glutamatergic transmission in schizophrenia. Interestingly, the amygdala, where marked PNN decreases were detected in schizophrenia, is particularly enriched in tPA $[42,55,204-206]$. MMP-9 has also been shown to powerfully regulate synaptic plasticity and LTP in particular, a role mediated by 1-containing integrin receptors [207]. Interestingly, MMP-9 is transiently released in response to enhanced neuronal activity and impacts both synaptic potentiation and dendritic spine enlargement in a dependent manner [207, 208]. As discussed above, the possibility that MMP-9, as well as other MMPs with potentially related functions, may represent genetic vulnerabilities in schizophrenia has been gaining evidence in recent times [98, 208-210].

2.5. Loss of Dendritic Spines in Schizophrenia. Marked reductions of dendritic spines have been consistently reported in schizophrenia, encompassing several cortical areas, including prefrontal and auditory cortical areas and the hippocampus [104, 109-111, 211]. In addition, the expression of postsynaptic density (PSD) proteins, such as PSD95 and Homer-1, and associated glutamate signaling pathway proteins has been shown to be altered in subjects with this disorder, as well as with autism spectrum disorders $[107,108]$. In support of the idea that these changes reflect a structural loss of dendritic spines, altered expression of molecules involved in the actin cytoskeleton has been reported in subjects with schizophrenia $[102,103,105]$.
2.6. Potential Contribution of ECM Abnormalities to Loss of Dendritic Spines. Dendritic spines contain the membraneassociated postsynaptic density (PSD) and its associated network of neurotransmitter receptors and downstream signaling molecules and are supported by a mesh of filamentous F-actin and scaffolding proteins [212-218]. ECM proteins, their surface receptors, and remodeling ECM enzymes play a critical role in regulating dendritic spine plasticity in adulthood (see review by [197]). CAMs, among which integrins are perhaps the most well studied, link the PSD to the actin cytoskeleton on one side and to the ECM and presynaptic terminal on the other side. Through this arrangement, CAMs mediate ECM and PSD signaling, influencing the dendritic spine actin network and thus the spine shape [219-225]. In turn, the spine size has a direct impact on synaptic strength, as larger spines/PSDs containing more numerous glutamate receptors have stronger effects on neuronal excitation and signal transmission [212, 226-232].

Several ECM molecules found to modulate spine formation, size, and stability through ECM receptors are also implicated in the pathology of schizophrenia (see above). CSPGs have been shown to actively stabilize dendritic spines, while their removal by enzymatic digestion results in increased spine motility [233-236]. Reelin promotes spine remodeling, impacting not only spine size and stability, but also the number of synaptic contacts per spine, effects at least in part mediated by its receptor ApoER2 [237-242]. The potential contribution of decreased Reelin expression to dendritic spine decreases in schizophrenia has long been postulated [243, 244]. Semaphorin 3A, a secreted ECM molecule expressed in PNNs, exerts a powerful effect on synapses, possibly through its plexin and neuropilin receptors [38, 197, 245-248]. Finally, and importantly, ECM proteases including tPA and MMPs have been shown to robustly affect dendritic spine stability [197]. tPA decreases spine stability, and its activation increases spine loss [249, 250]. This effect is particularly interesting as it relates to the impact of chronic stress in the amygdala and hippocampus, where tPA knockout decreases stress-induced spine loss [249, 250]. During development, MMPs play a key role in spine formation and maturation $[197,251,252]$. In mature neurons, MMPs, and their interactions with integrins, are required for spine volume changes induced by LTP and LTD [207, 253].

In summary, ECM molecules and their cell surface receptors mediate a broad range of synaptic regulatory functions impacting glutamatergic and GABAergic synapses, inhibitory neurons, and dendritic spine plasticity on excitatory neurons. The expression of several ECM molecules and their receptors involved in these functions has been shown to be altered in subjects with schizophrenia. Overall, these considerations support the hypothesis that ECM/PNN abnormalities in this disorder may disrupt synaptic functions and plasticity, perhaps leading to a dysregulation of inhibitory circuits and synaptic instability. The impact of these abnormalities is likely to be region specific, given the heterogeneous representation of these molecules in cortical and subcortical regions (e.g., $[42,55,204-206,254])$. 


\section{ECM Pathology in Autism Spectrum Disorders}

Multiple lines of evidence implicate ECM abnormalities in autism spectrum disorders, a heterogeneous group of neurodevelopmental disorders characterized by persistent deficits in social communication and social interaction and restricted, repetitive patterns of behavior, interests, or activities. Synaptic pathology is a well-established core pathological component of these disorders (e.g., [16]). Genetic studies have identified several ECM and related molecules as potential contributors to the etiology of autism. Analysis of six genome-wide association studies (GWAS) on autism implicates a number of ECM and PNN regulating molecules, including the ECM remodeling enzymes ADAMTS3, ADAMTS5, ADAMTS14, ECM molecules RELN, SEM3A, SEM4D, the hyaluronan surface receptor CD44, and OTX2, a transcription factor involved in PNN formation [255-263].

By far the strongest evidence for ECM involvement in the pathophysiology of autism comes from investigations on Reelin. GWAS, several association studies specifically investigating Reelin involvement in autism, and a metaanalysis report point to Reelin as a vulnerability gene for autism [257, 264-272]. Consistent with these findings, altered expression of Reelin and Reelin signaling pathways has been observed in the frontal, parietal, and cerebellar cortices of subjects with autism [273-275]. Reduced Reelin levels have also been shown in blood samples from subjects with this disorder [273]. Finally, the "reeler" mouse, which carries an autosomal recessive mutation in the Reelin gene, displays neurodevelopmental deficits reminiscent of psychiatric disorders including autism [273].

Emerging evidence suggests a role for heparan sulfate proteoglycans (HSPGs) in the pathophysiology of autism. Decreased HSPG expression was reported in the subventricular zone of subjects with autism [276]. Notably, this decrease was associated with increased neurogenesis in comparison to age-matched controls [276]. These findings are in agreement with an animal model of autism, the BTBR $\mathrm{T}+\mathrm{tf} / \mathrm{J}$ mouse, characterized by abnormal social behavior, communication deficits, and repetitive stereotyped behaviors as well as altered heparan sulfate expression in the subventricular zone, smaller amygdala volume, and other neurodevelopmental deficits reminiscent of those detected in autism [277-280]. Mutant mice lacking heparan sulfate show many features reflective of autism, including impaired social interaction, repetitive behavior, and deficits in ultrasonic vocalization [281]. Taken together, decreased heparan sulfate in autism may contribute to neurodevelopmental abnormalities focused on areas of cell proliferation as well as regions involved in memory and emotional processing.

\section{ECM Pathology in Fragile-X Syndrome}

Fragile-X is a single gene, inherited intellectual disability with predominant autistic symptoms [282-284]. The role that MMP-9 plays in the pathophysiology of this disorder represents a compelling example of interactions between
ECM molecules and synaptic pathology in psychiatric disorders. Fragile-X results from transcriptional silencing of the Fmrl gene, which encodes for the mRNA binding protein "Fragile-X mental retardation protein" (FMRP) (for review see [285]). FMRP controls, in an activity-dependent manner, mRNAs encoding for pre- and postsynaptic proteins, scaffolding proteins, neurotransmitter receptors, and signaling molecules [286, 287]. Decreased FMRP expression results in elevated protein synthesis at the synapse, with loss of regulation by neuronal activity, increase in neuronal excitability, and immature, abnormal spine morphology [285, 288-293]. Converging evidence indicates that the interactions between FMRP and the matrix metalloproteinase MMP-9, known to play a role in dendritic spine plasticity in an activitydependent manner [192, 294], may be critical to these synaptic abnormalities. Recent findings show that FMRP regulates the transport and translation of MMP-9 mRNA within the synapse: decreased FMRP results in increased MMP-9 [295]. Consistently, increased levels of MMP-9 have been reported in Fragile-X syndrome subjects while pharmacologically induced MMP-9 decrease leads to some degree of clinical improvement [296]. Elevated levels of MMP-9 were reported in the amnionic fluid of subjects who went on to develop autism later in life, including a subset of individuals without Fragile-X syndrome [297]. In parallel, Fmrl knockout mice present with delayed dendritic spine maturation, increased MMP-9, and Fragile-X associated behaviors [295, 298, 299]. Genetic or pharmacological disruption of MMP-9 expression in these mice rescues many of these abnormalities, including dendritic spine maturation and behavioral deficits $[299,300]$.

\section{ECM Pathology in Rett Syndrome}

Rett syndrome is a neurodevelopmental disorder characterized by stereotypical hand movements, language regression, decreased rate of brain growth, autonomic dysfunction, and seizures [301]. Deficits in dendritic spines and synaptic plasticity have been consistently reported in subjects with Rett syndrome and in animal models of this disorder [302306]. Rett syndrome is caused by a de novo genetic mutation in the X-linked methyl-CpG-binding protein 2 gene (MeCP2) [301, 307, 308]. Increased mRNA for RELN was reported in MeCP2 mutant mice [309]. Furthermore, increased PNN labeling with WFA was observed in the motor cortex of subjects with Rett syndrome [310]. Notably, these changes are opposite to those observed in autism and schizophrenia, suggesting that different patterns of pathological deviations of ECM composition may result in synaptic abnormalities, such as those detected in these disorders.

\section{ECM Pathology in Mood Disorders}

Mood disorders are a category of psychiatric disorders characterized by a persistent altered emotional state; they include bipolar disorder and major depression. Involvement of ECM molecules, and presence of synaptic pathology, in these disorders has been extensively documented $[15,55,67$, 311-315]. For instance, decreased Reelin expression has been 
reported in the prefrontal cortex, hippocampus, and cerebellum, as well as in blood, of subjects with bipolar disorder or major depression [311, 313, 316, 317]. Our postmortem studies in bipolar disorder show marked decreased of CS-6(3B3)immunolabeled PNNs across several nuclei in the amygdala, while more moderate decreases of aggrecan-immunolabeled PNNs were observed in the accessory basal nucleus of the amygdala [55]. Furthermore, similar to schizophrenia and autism, increased levels of MMP-9 have been reported in blood samples from subjects with major depression and young subjects with bipolar disorder in a depressed state $[91,318,319]$. GWAS in bipolar disorder have identified a genetic variant of NCAN, encoding for the CSPG neurocan, as a risk factor for this disorder [314]. Consistently, NCAN gene variants are associated with manic symptoms in human subjects [320], and NCAN knockout in mice results in maniclike behaviors [320].

Intriguingly, some of the most effective treatments for mood disorders impact ECM molecules and PNN composition. For example, chronic treatment with the selective serotonin reuptake inhibitor fluoxetine, effective in treating depression and anxiety, results in decreased numbers of WFA-labeled PNNs in the hippocampus and medial prefrontal cortex of mice, accompanied by increased immature neuronal markers and dendritic spine density on interneurons [321, 322]. Fluoxetine exposure in utero has also been shown to delay the formation of PNNs during adolescence in the amygdala and hippocampus of mice [323]. Lithium, one of the most effective treatments for bipolar disorder, contributes to CSPG digestion [324, 325]. Consistently, numbers of "glial clusters" labeled with a CS-6 specific antibody (CS56), shown to be decreased in the amygdala of subjects with bipolar disorder, showed a positive correlation with lifetime exposure to lithium, raising the possibility that chronic lithium exposure may exert therapeutic effects on CSPG sulfation patterns in bipolar disorder [55].

\section{ECM Pathology in Alzheimer's Disease}

Alzheimer's disease, an irreversible late life brain disorder that progressively disrupts memory and independent living skills, is associated with dendritic spine loss [326-328]. A key neuropathological feature in Alzheimer's disease is the formation of $\beta$-amyloid plaques associated with mutations in the presenilin-1 and presenilin-2 genes $[329,330]$. These plaques are generated by cleavage of the amyloid precursor protein (APP) by $\beta$-site APP cleaving enzyme-1 (BACE1) [331]. Converging evidence points to a role for HSPGs and CSPGs in the formation of amyloid plaques. Heparan sulfates regulate cleavage of APP by BACE1, and several HSPGs, including syndecan, glypican, and agrin, can be detected within amyloid plaques [332-340]. Notably, syndecan is involved in the formation of dendritic spines [341-344]. Finally, increased expression of HSPGs has been reported in postmortem brain samples from subjects with $\mathrm{AD}$ [335-338, $345,346]$. CSPGs, specifically CS-4, CS-6, and nonsulfated CS, have also been reported in $\beta$-amyloid plaques [347]. Intriguingly, a splice variant of APP corresponds to the CSPG appican, expressed primarily by astrocytes in the brain [5, 348]. Interestingly, APP cleavage by ADAM10 results in a beneficial form, amyloid- $\alpha$, and in turn suppresses amyloid$\beta$ [349]. Physiologically, ADAM10 and APP are highly concentrated at the PSD site and are involved in the regulation of synaptic plasticity [350], suggesting that disrupted levels of amyloid $-\alpha$ and amyloid- $\beta$ in Alzheimer's disease may contribute to synaptic deficits. Similarly, MMP-9 has been reported to cleave APP through $\alpha$-secretase activity, thus promoting the nonamyloidogenic form and functioning as a protective factor from amyloid- $\beta$ accumulation and subsequent cognitive deficits, accompanied by increased levels of presynaptic proteins $[351,352]$. Furthermore, MMP-9 has been shown to degrade extracellular amyloid- $\beta$ in amyloid plaques, providing further protection against $\mathrm{AD}$ pathology $[353,354]$.

Of relevance to this review, decreased densities of PNNs have been reported in Alzheimer's disease [355]. In particular, decreased WFA-labeled PNNs were observed in the frontal cortex of subjects with Alzheimer's disease, while densities of neurons expressing PVB were not altered [355]. These findings are in agreement with data from our group, showing dramatic decreased numbers and degraded morphology of WFA-labeled PNNs in the entorhinal cortex of Alzheimer's disease patients (Figure 4, unpublished results). Other authors have suggested that aggrecan-containing PNNs may play a protective role against tau pathology in Alzheimer's disease [356].

\section{ECM Pathology in Epilepsy}

Epilepsy encompasses a spectrum of severe to benign brain disorders characterized by disturbances of the normal pattern of neuronal activity, causing unusual emotions, behaviors, sensations, or sometimes loss of consciousness, convulsions, and muscle spasms. Compelling evidence from animal models supports the involvement of the ECM in seizure disorders. The ECM undergoes extensive remodeling in response to seizures, including increased production of CSPGs by glial cells, and cleavage of CSPGs by MMPs [357-362]. As part of such ECM remodeling, PNNs are decreased, at least in part as a consequence to aggrecan cleavage by MMPs $[357,358]$. It has been proposed that ECM remodeling may allow for synaptic reorganization, such as it occurs following seizures $[36,363]$. Conversely, intriguing evidence suggests that ECM abnormalities may contribute to susceptibility to seizures. For example, enzymatic PNN digestion lowers the threshold for seizure induction [358]. Similarly, inhibition of MMP activity prevents seizure induction and PNN breakdown in an amygdala kindled seizure model [363]. Kainic acidinduced seizures trigger short term CSPG changes followed by more prolonged ones, resulting in altered neurocan and phosphacan levels in limbic brain regions; this latter phase coincides with increases of spontaneous recurrent seizures [357]. In addition, mice lacking the hyaluronan synthesizing enzyme Has3 present with reduced extracellular space and display increased epileptic activity [364]. Further evidence 


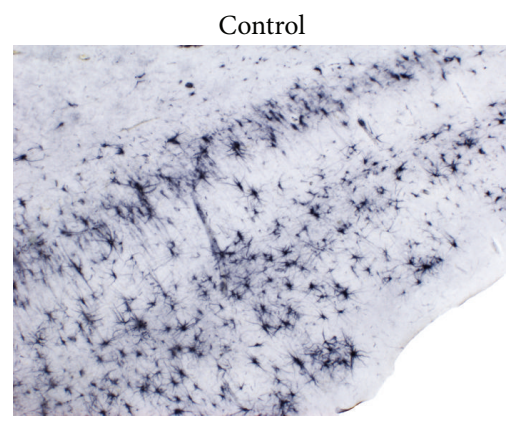

(a)

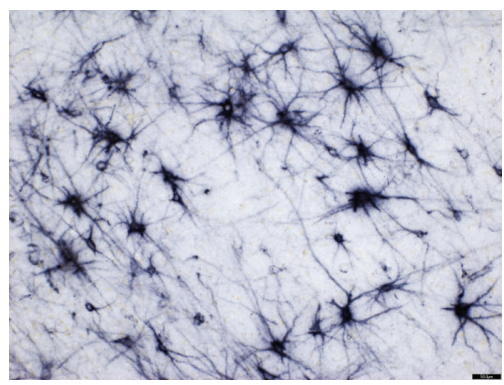

(c)

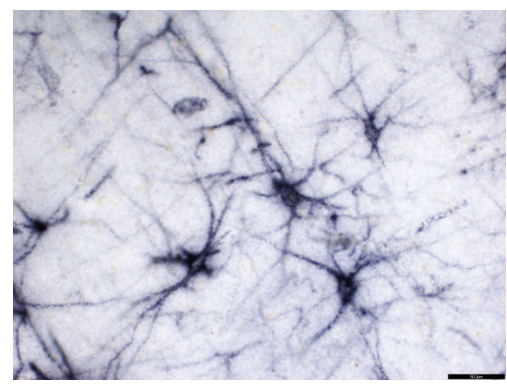

(e)

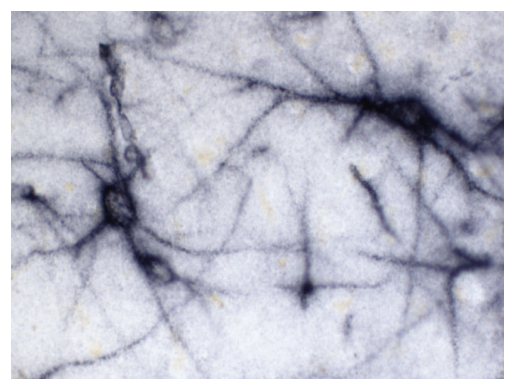

(g)

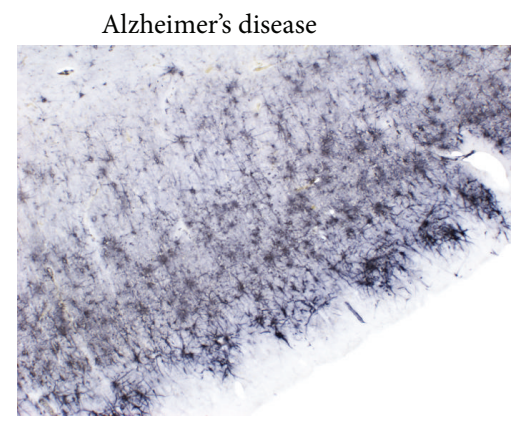

(b)

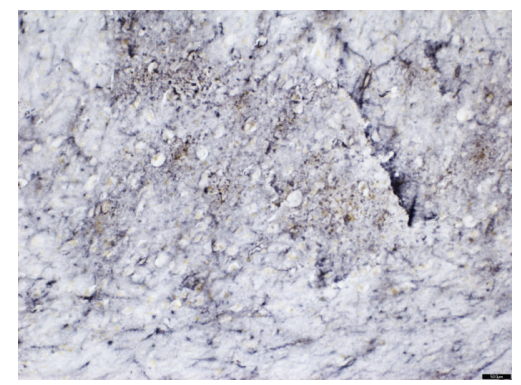

(d)

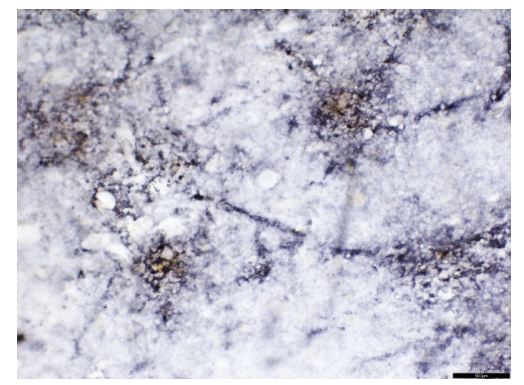

(f)

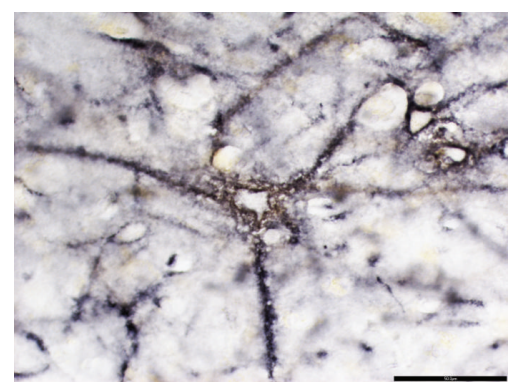

(h)

FIGURE 4: PNN structure is altered in Alzheimer's disease. Examples of WFA-labeled PNNs in the entorhinal cortex of healthy subjects (a, c, e, g) and subjects with Alzheimer's disorder (b, d, f, h). In healthy subjects, WFA-labeled PNNs are distributed across all layers of the ECx, with preferential concentration in layers II-III and layers V-VI (a). In subjects with Alzheimer's disease, WFA labeling appears to be more loosely distributed, in aggregates throughout the ECx, often suggestive of degraded PNNs (b, d, f, h).

that ECM abnormalities contribute to seizure susceptibility comes from studies on MMP-9. Levels of MMP-9 are increased in blood samples from subjects with epilepsy [365367]. Mice lacking MMP-9 are less susceptible to induction of seizures, whereas rats overexpressing MMP-9 are more susceptible [368]. MMP-9 has been proposed as a potential therapeutic target for this disorder [365].
It is interesting to note that seizures are often comorbid with several of the disorders discussed above, including autism, schizophrenia, Fragile-X, and Rett syndrome, each presenting with ECM abnormalities. Particularly frequent in these disorders are altered levels of MMP-9 and PNN numbers [369-378]. Given the compelling relationship between ECM molecules and seizures, such comorbidity may not be 
surprising and, on a speculative level, may point to partially shared mechanisms.

\section{Conclusions}

The role of PNNs, and more in general ECM, represents an emerging field in the pathophysiology of psychiatric disorders. Evolving in parallel with a growing understanding of the role of the ECM in the regulation of synaptic plasticity, this field is beginning to integrate the concept of the quadripartite synapse in hypotheses on the pathophysiology of synaptic dysregulation in these disorders. Overlapping patterns of ECM abnormalities, in disorders that also share clinical features and synaptic deficits, may underlie common "end-point" mechanisms; that is, anomalies affecting one or more elements of functionally similar molecular families in each of these disorders may lead to convergent effects on synaptic functions and, potentially, clinical domains. Cell and regional specificity may be determined by nonoverlapping pathological aspects in each disorder, as well as by neurodevelopmental determinants specifying the age range at which these anomalies become pathologically relevant.

\section{Conflict of Interests}

The authors declare that there is no conflict of interests regarding the publication of this paper.

\section{References}

[1] S. Berretta, "Extracellular matrix abnormalities in schizophrenia," Neuropharmacology, vol. 62, no. 3, pp. 1584-1597, 2012.

[2] S. Berretta, H. Pantazopoulos, M. Markota, C. Brown, and E. T. Batzianouli, "Losing the sugar coating: potential impact of perineuronal net abnormalities on interneurons in schizophrenia," Schizophrenia Research, vol. 16, no. 1-3, pp. 18-27, 2015.

[3] B. K. Y. Bitanihirwe and T.-U. W. Woo, "Perineuronal nets and schizophrenia: the importance of neuronal coatings," Neuroscience \& Biobehavioral Reviews, vol. 45, pp. 85-99, 2014.

[4] T. D. Folsom and S. H. Fatemi, "The involvement of Reelin in neurodevelopmental disorders," Neuropharmacology, vol. 68, pp. 122-135, 2013.

[5] M. N. Pangalos, J. Shioi, S. Efthimiopoulos, A. Wu, and N. K. Robakis, "Characterization of appican, the chondroitin sulfate proteoglycan form of the Alzheimer amyloid precursor protein," Neurodegeneration, vol. 5, no. 4, pp. 445-451, 1996.

[6] T. A. Kato, M. Watabe, and S. Kanba, "Neuron-glia interaction as a possible glue to translate the mind-brain gap: a novel multi-dimensional approach toward psychology and psychiatry," Frontiers in Psychiatry, vol. 4, article 139, 2013.

[7] M. Prinz and J. Priller, "Microglia and brain macrophages in the molecular age: from origin to neuropsychiatric disease," Nature Reviews Neuroscience, vol. 15, no. 5, pp. 300-312, 2014.

[8] K. Yamamuro, S. Kimoto, K. M. Rosen, T. Kishimoto, and M. Makinodan, "Potential primary roles of glial cells in the mechanisms of psychiatric disorders," Frontiers in Cellular Neuroscience, vol. 9, article 154, 2015.

[9] A. Dityatev, C. I. Seidenbecher, and M. Schachner, "Compartmentalization from the outside: the extracellular matrix and functional microdomains in the brain," Trends in Neurosciences, vol. 33, no. 11, pp. 503-512, 2010.

[10] N. John, H. Krügel, R. Frischknecht et al., "Brevican-containing perineuronal nets of extracellular matrix in dissociated hippocampal primary cultures," Molecular and Cellular Neuroscience, vol. 31, no. 4, pp. 774-784, 2006.

[11] A. Faissner, M. Pyka, M. Geissler et al., "Contributions of astrocytes to synapse formation and maturation-potential functions of the perisynaptic extracellular matrix," Brain Research Reviews, vol. 63, no. 1-2, pp. 26-38, 2010.

[12] A. Dityatev and D. A. Rusakov, "Molecular signals of plasticity at the tetrapartite synapse," Current Opinion in Neurobiology, vol. 21, no. 2, pp. 353-359, 2011.

[13] A. Heikkinen, T. Pihlajaniemi, A. Faissner, and M. Yuzaki, "Neural ECM and synaptogenesis," Progress in Brain Research, vol. 214, pp. 29-51, 2014.

[14] A. C. Smith, M. D. Scofield, and P. W. Kalivas, "The tetrapartite synapse: extracellular matrix remodeling contributes to corticoaccumbens plasticity underlying drug addiction," Brain Research, 2015.

[15] A. J. Williams and H. Umemori, "The best-laid plans go oft awry: synaptogenic growth factor signaling in neuropsychiatric disease," Frontiers in Synaptic Neuroscience, vol. 6, article 4, 2014.

[16] P. Penzes, A. Buonanno, M. Passafaro, C. Sala, and R. A. Sweet, "Developmental vulnerability of synapses and circuits associated with neuropsychiatric disorders," Journal of Neurochemistry, vol. 126, no. 2, pp. 165-182, 2013.

[17] Y. Bernardinelli, I. Nikonenko, and D. Muller, "Structural plasticity: mechanisms and contribution to developmental psychiatric disorders," Frontiers in Neuroanatomy, vol. 8, article 123, 2014.

[18] D. C. Rotaru, D. A. Lewis, and G. Gonzalez-Burgos, “The role of glutamatergic inputs onto parvalbumin-positive interneurons: relevance for schizophrenia," Reviews in the Neurosciences, vol. 23, no. 1, pp. 97-109, 2012.

[19] R. S. Duman, "Pathophysiology of depression and innovative treatments: remodeling glutamatergic synaptic connections," Dialogues in Clinical Neuroscience, vol. 16, no. 1, pp. 11-27, 2014.

[20] X. Xu, E. C. Miller, and L. Pozzo-Miller, "Dendritic spine dysgenesis in Rett syndrome," Frontiers in Neuroanatomy, vol. 8, article 97, 2014.

[21] S. W. Scheff, J. H. Neltner, and P. T. Nelson, "Is synaptic loss a unique hallmark of Alzheimer's disease?" Biochemical Pharmacology, vol. 88, no. 4, pp. 517-528, 2014.

[22] F. Tissir and A. M. Goffinet, "Reelin and brain development," Nature Reviews Neuroscience, vol. 4, no. 6, pp. 496-505, 2003.

[23] D. R. Zimmermann and M. T. Dours-Zimmermann, "Extracellular matrix of the central nervous system: from neglect to challenge," Histochemistry and Cell Biology, vol. 130, no. 4, pp. 635-653, 2008.

[24] R. J. Giger, E. R. Hollis II, and M. H. Tuszynski, "Guidance molecules in axon regeneration," Cold Spring Harbor Perspectives in Biology, vol. 2, no. 7, Article ID a001867, 2010.

[25] N. Maeda, N. Fukazawa, and M. Ishii, "Chondroitin sulfate proteoglycans in neural development and plasticity," Frontiers in Bioscience, vol. 15, pp. 626-644, 2010.

[26] C. S. Barros, S. J. Franco, and U. Müller, "Extracellular matrix: functions in the nervous system," Cold Spring Harbor perspectives in biology, vol. 3, no. 1, Article ID a005108, 2011.

[27] S. J. Franco and U. Müller, "Extracellular matrix functions during neuronal migration and lamination in the mammalian 
central nervous system," Developmental Neurobiology, vol. 71, no. 11, pp. 889-900, 2011.

[28] J. C. F. Kwok, G. Dick, D. Wang, and J. W. Fawcett, "Extracellular matrix and perineuronal nets in CNS repair," Developmental Neurobiology, vol. 71, no. 11, pp. 1073-1089, 2011.

[29] S. Sirko, A. von Holst, A. Wizenmann, M. Götz, and A. Faissner, "Chondroitin sulfate glycosaminoglycans control proliferation, radial glia cell differentiation and neurogenesis in neural stem/progenitor cells," Development, vol. 134, no. 15, pp. 27272738, 2007.

[30] C. E. Bandtlow and D. R. Zimmermann, "Proteoglycans in the developing brain: new conceptual insights for old proteins," Physiological Reviews, vol. 80, no. 4, pp. 1267-1290, 2000.

[31] S. Berretta, "Astrocytes in the pathophysiology of schizophrenia: abnormal expression of extracellular matrix molecules," Schizophrenia Research, vol. 102, supplement 2, no. 1-3, p. 11, 2008.

[32] K. E. Rhodes and J. W. Fawcett, "Chondroitin sulphate proteoglycans: preventing plasticity or protecting the CNS?” Journal of Anatomy, vol. 204, no. 1, pp. 33-48, 2004.

[33] E. Syková, "Diffusion properties of the brain in health and disease," Neurochemistry International, vol. 45, no. 4, pp. 453466, 2004.

[34] M. S. Viapiano and R. T. Matthews, "From barriers to bridges: chondroitin sulfate proteoglycans in neuropathology," Trends in Molecular Medicine, vol. 12, no. 10, pp. 488-496, 2006.

[35] S. H. Fatemi, "Co-occurrence of neurodevelopmental genes in etiopathogenesis of autism and schizophrenia," Schizophrenia Research, vol. 118, no. 1-3, pp. 303-304, 2010.

[36] P. A. McRae and B. E. Porter, "The perineuronal net component of the extracellular matrix in plasticity and epilepsy," Neurochemistry International, vol. 61, no. 7, pp. 963-972, 2012.

[37] B. R. Lubbers, A. B. Smit, S. Spijker, and M. C. van den Oever, "Neural ECM in addiction, schizophrenia, and mood disorder," Progress in Brain Research, vol. 214, pp. 263-284, 2014.

[38] J. W. Fawcett, "The extracellular matrix in plasticity and regeneration after CNS injury and neurodegenerative disease," in Progress in Brain Research, vol. 218, chapter 10, pp. 213-226, Elsevier, 2015.

[39] N. Takahashi, T. Sakurai, O. Bozdagi-Gunal et al., "Increased expression of receptor phosphotyrosine phosphatase- $\beta / \zeta$ is associated with molecular, cellular, behavioral and cognitive schizophrenia phenotypes," Translational Psychiatry, vol. 1, article e8, 2011.

[40] A. Shah and D. J. Lodge, "A loss of hippocampal perineuronal nets produces deficits in dopamine system function: relevance to the positive symptoms of schizophrenia," Translational Psychiatry, vol. 3, article e215, 2013.

[41] J.-H. Cabungcal, P. Steullet, H. Morishita et al., "Perineuronal nets protect fast-spiking interneurons against oxidative stress," Proceedings of the National Academy of Sciences of the United States of America, vol. 110, no. 22, pp. 9130-9135, 2013.

[42] H. Pantazopoulos, T.-U. W. Woo, M. P. Lim, N. Lange, and S. Berretta, "Extracellular matrix-glial abnormalities in the amygdala and entorhinal cortex of subjects diagnosed with schizophrenia," Archives of General Psychiatry, vol. 67, no. 2, pp. 155-166, 2010.

[43] S. Berretta, H. Pantazopoulos, and N. Lange, "Neuron numbers and volume of the amygdala in subjects diagnosed with bipolar disorder or schizophrenia," Biological Psychiatry, vol. 62, no. 8, pp. 884-893, 2007.
[44] P. Lavenex and D. G. Amaral, "Hippocampal-neocortical interaction: a hierarchy of associativity," Hippocampus, vol. 10, no. 4, pp. 420-430, 2000.

[45] M. de Curtis and D. Paré, “The rhinal cortices: a wall of inhibition between the neocortex and the hippocampus," Progress in Neurobiology, vol. 74, no. 2, pp. 101-110, 2004.

[46] K. M. R. Prasad, A. R. Patel, S. Muddasani, J. Sweeney, and M. S. Keshavan, "The entorhinal cortex in first-episode psychotic disorders: a structural magnetic resonance imaging study," The American Journal of Psychiatry, vol. 161, no. 9, pp. 1612-1619, 2004.

[47] A. Aleman and R. S. Kahn, "Strange feelings: do amygdala abnormalities dysregulate the emotional brain in schizophrenia?" Progress in Neurobiology, vol. 77, no. 5, pp. 283-298, 2005.

[48] H. Pantazopoulos, N. Lange, L. Hassinger, and S. Berretta, "Subpopulations of neurons expressing parvalbumin in the human amygdala," Journal of Comparative Neurology, vol. 496, no. 5, pp. 706-722, 2006.

[49] W. Hartig, K. Brauer, and G. Bruckner, "Wisteria floribunda agglutinin-labelled nets surround parvalbumin-containing neurons," NeuroReport, vol. 3, no. 10, pp. 869-872, 1992.

[50] M. R. Celio, "Perineuronal nets of extracellular matrix around parvalbumin-containing neurons of the hippocampus," Hippocampus, vol. 3, pp. 55-60, 1993.

[51] G. Bruckner, G. Seeger, K. Brauer, W. Hartig, J. Kacza, and V. Bigl, "Cortical areas are revealed by distribution patterns of proteoglycan components and parvalbumin in the Mongolian gerbil and rat," Brain Research, vol. 658, no. 1-2, pp. 67-86, 1994.

[52] W. Härtig, K. Brauer, V. Bigl, and G. Brückner, "Chondroitin sulfate proteoglycan-immunoreactivity of lectin-labeled perineuronal nets around parvalbumin-containing neurons," Brain Research, vol. 635, no. 1-2, pp. 307-311, 1994.

[53] N. P. Morris and Z. Henderson, "Perineuronal nets ensheath fast spiking, parvalbumin-immunoreactive neurons in the medial septum/diagonal band complex," European Journal of Neuroscience, vol. 12, no. 3, pp. 828-838, 2000.

[54] L. Vitellaro-Zuccarello, A. Meroni, A. Amadeo, and S. De Biasi, "Chondroitin sulfate proteoglycans in the rat thalamus: expression during postnatal development and correlation with calcium-binding proteins in adults," Cell and Tissue Research, vol. 306, no. 1, pp. 15-26, 2001.

[55] H. Pantazopoulos, M. Markota, F. Jaquet et al., "Aggrecan and chondroitin-6-sulfate abnormalities in schizophrenia and bipolar disorder: a postmortem study on the amygdala," Translational Psychiatry, vol. 5, no. 1, article e496, 2015.

[56] S. A. Mauney, K. M. Athanas, H. Pantazopoulos et al., "Developmental pattern of perineuronal nets in the human prefrontal cortex and their deficit in schizophrenia," Biological Psychiatry, vol. 74, no. 6, pp. 427-435, 2013.

[57] H. Pantazopoulos, A. Boyer-Boiteau, E. H. Holbrook et al., "Proteoglycan abnormalities in olfactory epithelium tissue from subjects diagnosed with schizophrenia," Schizophrenia Research, vol. 150, no. 2-3, pp. 366-372, 2013.

[58] J. D. Buxbaum, L. Georgieva, J. J. Young et al., "Molecular dissection of NRG1-ERBB4 signaling implicates PTPRZ1 as a potential schizophrenia susceptibility gene," Molecular Psychiatry, vol. 13, no. 2, pp. 162-172, 2008.

[59] H. Kawachi, H. Tamura, I. Watakabe, T. Shintani, N. Maeda, and M. Noda, "Protein tyrosine phosphatase zeta/RPTPbeta interacts with PSD-95/SAP90 family," Brain Research. Molecular Brain Research, vol. 72, no. 1, pp. 47-54, 1999. 
[60] S. E. Snyder, J. Li, P. E. Schauwecker, T. H. McNeill, and S. R. J. Salton, "Comparison of RPTP $\zeta / \beta$, phosphacan, and trkB mRNA expression in the developing and adult rat nervous system and induction of RPTP $\zeta / \beta$ and phosphacan mRNA following brain injury," Molecular Brain Research, vol. 40, no. 1, pp. 79-96, 1996.

[61] T. Nishiwaki, N. Maeda, and M. Noda, "Characterization and developmental regulation of proteoglycan-type protein tyrosine phosphatase zeta/RPTPbeta isoforms," Journal of Biochemistry, vol. 123, no. 3, pp. 458-467, 1998.

[62] T. Shintani, E. Watanabe, N. Maeda, and M. Noda, "Neurons as well as astrocytes express proteoglycan-type protein tyrosine phosphatase $\zeta / R P T P \beta$ : analysis of mice in which the $P T P \zeta / R P T P \beta$ gene was replaced with the LacZ gene," Neuroscience Letters, vol. 247, no. 2-3, pp. 135-138, 1998.

[63] K. Niisato, A. Fujikawa, S. Komai et al., "Age-dependent enhancement of hippocampal long-term potentiation and impairment of spatial learning through the Rho-associated kinase pathway in protein tyrosine phosphatase receptor type Z-deficient mice," The Journal of Neuroscience, vol. 25, no. 5, pp. 1081-1088, 2005.

[64] T. W. Mühleisen, M. Mattheisen, J. Strohmaier et al., "Association between schizophrenia and common variation in neurocan (NCAN), a genetic risk factor for bipolar disorder," Schizophrenia Research, vol. 138, no. 1, pp. 69-73, 2012.

[65] Schizophrenia Working Group of the Psychiatric Genomics Consortium, "Biological insights from 108 schizophreniaassociated genetic loci,” Nature, vol. 511, no. 7510, pp. 421-427, 2014.

[66] S. L. Eastwood, A. J. Law, I. P. Everall, and P. J. Harrison, "The axonal chemorepellant semaphorin $3 \mathrm{~A}$ is increased in the cerebellum in schizophrenia and may contribute to its synaptic pathology," Molecular Psychiatry, vol. 8, no. 2, pp. 148-155, 2003.

[67] A. Guidotti, J. Auta, J. M. Davis et al., "Decrease in reelin and glutamic acid decarboxylase67 (GAD67) expression in schizophrenia and bipolar disorder: a postmortem brain study," Archives of General Psychiatry, vol. 57, no. 11, pp. 1061-1069, 2000.

[68] G. Habl, A. Schmitt, M. Zink et al., "Decreased reelin expression in the left prefrontal cortex (BA9) in chronic schizophrenia patients," Neuropsychobiology, vol. 66, no. 1, pp. 57-62, 2012.

[69] L. Harvey and P. Boksa, "A stereological comparison of GAD67 and reelin expression in the hippocampal stratum oriens of offspring from two mouse models of maternal inflammation during pregnancy," Neuropharmacology, vol. 62, no. 4, pp. 17671776, 2012.

[70] F. Impagnatiello, A. R. Guidotti, C. Pesold et al., "A decrease of reelin expression as a putative vulnerability factor in schizophrenia," Proceedings of the National Academy of Sciences of the United States of America, vol. 95, no. 26, pp. 15718-15723, 1998.

[71] E. Dong, R. C. Agis-Balboa, M. V. Simonini, D. R. Grayson, E. Costa, and A. Guidotti, "Reelin and glutamic acid decarboxylase $_{67}$ promoter remodeling in an epigenetic methionine-induced mouse model of schizophrenia," Proceedings of the National Academy of Sciences of the United States of America, vol. 102, no. 35, pp. 12578-12583, 2005.

[72] H. M. Abdolmaleky, K.-H. Cheng, A. Russo et al., "Hypermethylation of the reelin (RELN) promoter in the brain of schizophrenic patients: a preliminary report," American Journal of Medical Genetics B: Neuropsychiatric Genetics, vol. 134, no. 1, pp. 60-66, 2005.
[73] A. Guidotti, J. Auta, Y. Chen et al., "Epigenetic GABAergic targets in schizophrenia and bipolar disorder," Neuropharmacology, vol. 60, no. 7-8, pp. 1007-1016, 2011.

[74] A. Guidotti, W. Ruzicka, D. R. Grayson et al., "S-adenosyl methionine and DNA methyltransferase-1 mRNA overexpression in psychosis," Neuroreport, vol. 18, no. 1, pp. 57-60, 2007.

[75] S. L. Eastwood and P. J. Harrison, "Interstitial white matter neurons express less reelin and are abnormally distributed in schizophrenia: towards an integration of molecular and morphologic aspects of the neurodevelopmental hypothesis," Molecular Psychiatry, vol. 8, no. 9, pp. 821-831, 2003.

[76] S. Akbarian, W. E. Bunney Jr., S. G. Potkin et al., "Altered distribution of nicotinamide-adenine dinucleotide phosphatediaphorase cells in frontal lobe of schizophrenics implies disturbances of cortical development," Archives of General Psychiatry, vol. 50, no. 3, pp. 169-177, 1993.

[77] D. Arion, S. Horváth, D. A. Lewis, and K. Mirnics, "Infragranular gene expression disturbances in the prefrontal cortex in schizophrenia: signature of altered neural development?" Neurobiology of Disease, vol. 37, no. 3, pp. 738-746, 2010.

[78] T. Fujii, H. Uchiyama, N. Yamamoto et al., "Possible association of the semaphorin 3D gene (SEMA3D) with schizophrenia," Journal of Psychiatric Research, vol. 45, no. 1, pp. 47-53, 2011.

[79] S. Mah, M. R. Nelson, L. E. DeLisi et al., "Identification of the semaphorin receptor PLXNA2 as a candidate for susceptibility to schizophrenia," Molecular Psychiatry, vol. 11, no. 5, pp. 471478, 2006.

[80] T. Fujii, Y. Iijima, H. Kondo et al., "Failure to confirm an association between the PLXNA2 gene and schizophrenia in a Japanese population," Progress in Neuro-Psychopharmacology and Biological Psychiatry, vol. 31, no. 4, pp. 873-877, 2007.

[81] I. Supriyanto, Y. Watanabe, K. Mouri et al., "A missense mutation in the ITGA8 gene, a cell adhesion molecule gene, is associated with schizophrenia in Japanese female patients," Progress in Neuro-Psychopharmacology and Biological Psychiatry, vol. 40, no. 1, pp. 347-352, 2013.

[82] K.-S. Wang, X. Liu, T. B. Arana et al., "Genetic association analysis of ITGB3 polymorphisms with age at onset of schizophrenia," Journal of Molecular Neuroscience, vol. 51, no. 2, pp. 446-453, 2013.

[83] Y. Fan, G. Abrahamsen, R. Mills et al., "Focal adhesion dynamics are altered in schizophrenia," Biological Psychiatry, vol. 74, no. 6, pp. 418-426, 2013.

[84] M.-T. H. Walsh, M. Ryan, A. Hillmann et al., "Elevated expression of integrin alpha(IIb) beta(IIIa) in drug-naive, first-episode schizophrenic patients," Biological Psychiatry, vol. 52, no. 9, pp. 874-879, 2002.

[85] E. M. Muir, K. H. Adcock, D. A. Morgenstern et al., "Matrix metalloproteases and their inhibitors are produced by overlapping populations of activated astrocytes," Molecular Brain Research, vol. 100, no. 1-2, pp. 103-117, 2002.

[86] S. Porter, I. M. Clark, L. Kevorkian, and D. R. Edwards, "The ADAMTS metalloproteinases," Biochemical Journal, vol. 386, no. 1, pp. 15-27, 2005.

[87] R. Medina-Flores, G. Wang, S. J. Bissel, M. Murphey-Corb, and C. A. Wiley, "Destruction of extracellular matrix proteoglycans is pervasive in simian retroviral neuroinfection," Neurobiology of Disease, vol. 16, no. 3, pp. 604-616, 2004.

[88] C. Hobohm, A. Günther, J. Grosche, S. Roßner, D. Schneider, and G. Brückner, "Decomposition and long-lasting downregulation of extracellular matrix in perineuronal nets induced 
by focal cerebral ischemia in rats," Journal of Neuroscience Research, vol. 80, no. 4, pp. 539-548, 2005.

[89] M. Bajor and L. Kaczmarek, "Proteolytic remodeling of the synaptic cell adhesion molecules (CAMs) by metzincins in synaptic plasticity," Neurochemical Research, vol. 38, no. 6, pp. 1113-1121, 2013.

[90] P. Okulski, T. M. Jay, J. Jaworski et al., “TIMP-1 abolishes MMP-9-dependent long-lasting long-term potentiation in the prefrontal cortex," Biological Psychiatry, vol. 62, no. 4, pp. 359362, 2007.

[91] E. Domenici, D. R. Willé, F. Tozzi et al., "Plasma protein biomarkers for depression and schizophrenia by multi analyte profiling of case-control collections," PLoS ONE, vol. 5, no. 2, Article ID e9166, 2010.

[92] H. Yamamori, R. Hashimoto, T. Ishima et al., "Plasma levels of mature brain-derived neurotrophic factor (BDNF) and matrix metalloproteinase-9 (MMP-9) in treatment-resistant schizophrenia treated with clozapine," Neuroscience Letters, vol. 556, pp. 37-41, 2013.

[93] C. Y. Pietersen, S. A. Mauney, S. S. Kim et al., "Molecular profiles of pyramidal neurons in the superior temporal cortex in schizophrenia," Journal of Neurogenetics, vol. 28, no. 1-2, pp. 53-69, 2014.

[94] D. J. Dow, J. Huxley-Jones, J. M. Hall, and et al, "ADAMTSL3 as a candidate gene for schizophrenia: gene sequencing and ultrahigh density association analysis by imputation," Schizophrenia Research, vol. 127, no. 1-3, pp. 28-34, 2011.

[95] I. N. Bespalova, G. W. Angelo, B. P. Ritter et al., "Genetic variations in the ADAMTS12 gene are associated with schizophrenia in Puerto Rican patients of Spanish descent," NeuroMolecular Medicine, vol. 14, no. 1, pp. 53-64, 2012.

[96] L. M. McGrath, M. C. Cornelis, P. H. Lee et al., "Genetic predictors of risk and resilience in psychiatric disorders: a cross-disorder genome-wide association study of functional impairment in major depressive disorder, bipolar disorder, and schizophrenia," American Journal of Medical Genetics, Part B: Neuropsychiatric Genetics, vol. 162, no. 8, pp. 779-788, 2013.

[97] S. Ripke, A. R. Sanders, K. S. Kendler et al., "Genome-wide association study identifies five new schizophrenia loci," Nature Genetics, vol. 43, no. 10, pp. 969-976, 2011.

[98] S. Ripke, B. M. Neale, A. Corvin et al., "Biological insights from 108 schizophrenia-associated genetic loci," Nature, vol. 511, no. 7510, pp. 421-427, 2014.

[99] K. Q. Do, A. H. Trabesinger, M. Kirsten-Krüger et al., "Schizophrenia: glutathione deficit in cerebrospinal fluid and prefrontal cortex in vivo," European Journal of Neuroscience, vol. 12, no. 10, pp. 3721-3728, 2000.

[100] K. Q. Do, M. Cuenod, and T. K. Hensch, "Targeting oxidative stress and aberrant critical period plasticity in the developmental trajectory to schizophrenia," Schizophrenia Bulletin, vol. 41, no. 4, pp. 835-846, 2015.

[101] P. Steullet, J. Cabungcal, A. Monin et al., "Redox dysregulation, neuroinflammation, and NMDA receptor hypofunction: a 'central hub' in schizophrenia pathophysiology?” Schizophrenia Research, 2014.

[102] D. Datta, D. Arion, J. P. Corradi, and D. A. Lewis, "Altered expression of CDC42 signaling pathway components in cortical layer 3 pyramidal cells in schizophrenia," Biological Psychiatry, 2015.

[103] M. A. Shelton, J. T. Newman, H. Gu et al., "Loss of microtubuleassociated protein 2 immunoreactivity linked to dendritic spine loss in Schizophrenia," Biological Psychiatry, vol. 78, no. 6, pp. 374-385, 2015.

[104] G. T. Konopaske, N. Lange, J. T. Coyle, and F. M. Benes, "Prefrontal cortical dendritic spine pathology in schizophrenia and bipolar disorder," JAMA Psychiatry, vol. 71, no. 12, pp. 13231331, 2014.

[105] G. T. Konopaske, S. Subburaju, J. T. Coyle, and F. M. Benes, "Altered prefrontal cortical MARCKS and PPP1R9A mRNA expression in schizophrenia and bipolar disorder," Schizophrenia Research, vol. 164, no. 1-3, pp. 100-108, 2015.

[106] C. E. Moyer, M. A. Shelton, and R. A. Sweet, "Dendritic spine alterations in schizophrenia," Neuroscience Letters, vol. 601, pp. 46-53, 2015.

[107] M. L. MacDonald, Y. Ding, J. Newman et al., "Altered glutamate protein co-expression network topology linked to spine loss in the auditory cortex of schizophrenia," Biological Psychiatry, vol. 77, no. 11, pp. 959-968, 2015.

[108] A. De Bartolomeis, G. Latte, C. Tomasetti, and F. Iasevoli, "Glutamatergic postsynaptic density protein dysfunctions in synaptic plasticity and dendritic spines morphology: relevance to schizophrenia and other behavioral disorders pathophysiology, and implications for novel therapeutic approaches," Molecular Neurobiology, vol. 49, no. 1, pp. 484-511, 2014.

[109] L. A. Glantz and D. A. Lewis, "Decreased dendritic spine density on prefrontal cortical pyramidal neurons in schizophrenia," Archives of General Psychiatry, vol. 57, no. 1, pp. 65-73, 2000.

[110] A. J. Law, C. S. Weickert, T. M. Hyde, J. E. Kleinman, and P. J. Harrison, "Reduced spinophilin but not microtubuleassociated protein 2 expression in the hippocampal formation in schizophrenia and mood disorders: molecular evidence for a pathology of dendritic spines," The American Journal of Psychiatry, vol. 161, no. 10, pp. 1848-1855, 2004.

[111] N. S. Kolomeets, D. D. Orlovskaya, V. I. Rachmanova, and N. A. Uranova, "Ultrastructural alterations in hippocampal mossy fiber synapses in schizophrenia: a postmortem morphometric study," Synapse, vol. 57, no. 1, pp. 47-55, 2005.

[112] C. Le Magueresse and H. Monyer, "GABAergic interneurons shape the functional maturation of the cortex," Neuron, vol. 77, no. 3, pp. 388-405, 2013.

[113] H. Hu, J. Gan, and P. Jonas, "Fast-spiking, parvalbumin ${ }^{+}$ GABAergic interneurons: from cellular design to microcircuit function," Science, vol. 345, no. 6196, Article ID 1255263, 2014.

[114] D. M. Kullmann, A. W. Moreau, Y. Bakiri, and E. Nicholson, "Plasticity of inhibition," Neuron, vol. 75, no. 6, pp. 951-962, 2012.

[115] F. M. Benes and S. Berretta, "GABAergic interneurons: implications for understanding schizophrenia and bipolar disorder," Neuropsychopharmacology, vol. 25, no. 1, pp. 1-27, 2001.

[116] G. Gonzalez-Burgos and D. A. Lewis, "NMDA receptor hypofunction, parvalbumin-positive neurons, and cortical gamma oscillations in schizophrenia," Schizophrenia Bulletin, vol. 38, no. 5, pp. 950-957, 2012.

[117] J. T. Coyle, A. Basu, M. Benneyworth, D. Balu, and G. Konopaske, "Glutamatergic synaptic dysregulation in schizophrenia: therapeutic implications," in Handbook of Experimental Pharmacology, pp. 267-295, Springer, 2012.

[118] S. Akbarian and H.-S. Huang, "Molecular and cellular mechanisms of altered GAD1/GAD67 expression in schizophrenia and related disorders," Brain Research Reviews, vol. 52, no. 2, pp. 293-304, 2006. 
[119] S. Akbarian, M. M. Huntsman, J. J. Kim et al., " $G A B A_{A}$ receptor subunit gene expression in human prefrontal cortex: comparison of schizophrenics and controls," Cerebral Cortex, vol. 5, no. 6, pp. 550-560, 1995.

[120] F. M. Benes, "Altered glutamatergic and GABAergic mechanisms in the cingulate cortex of the schizophrenic brain," Archives of General Psychiatry, vol. 52, no. 12, pp. 1015-1024, 1995.

[121] E. Costa, J. M. Davis, E. Dong et al., "A GABAergic cortical deficit dominates schizophrenia pathophysiology," Critical Reviews in Neurobiology, vol. 16, no. 1-2, pp. 1-23, 2004.

[122] J. R. Glausier and D. A. Lewis, "Selective pyramidal cell reduction of $\mathrm{GABA}_{\mathrm{A}}$ receptor $\alpha 1$ subunit messenger RNA expression in schizophrenia," Neuropsychopharmacology, vol. 36, no. 10, pp. 2103-2110, 2011.

[123] A. Guidotti, J. Auta, J. M. Davis et al., "GABAergic dysfunction in schizophrenia: new treatment strategies on the horizon," Psychopharmacology, vol. 180, no. 2, pp. 191-205, 2005.

[124] T. Hashimoto, D. Arion, T. Unger et al., "Alterations in GABArelated transcriptome in the dorsolateral prefrontal cortex of subjects with schizophrenia," Molecular Psychiatry, vol. 13, no. 2, pp. 147-161, 2008.

[125] S. Kimoto, H. H. Bazmi, and D. A. Lewis, "Lower expression of glutamic acid decarboxylase 67 in the prefrontal cortex in schizophrenia: contribution of altered regulation by Zif268," The American Journal of Psychiatry, vol. 171, no. 9, pp. 969-978, 2014.

[126] D. A. Lewis, T. Hashimoto, and D. W. Volk, "Cortical inhibitory neurons and schizophrenia," Nature Reviews Neuroscience, vol. 6, no. 4, pp. 312-324, 2005.

[127] G. P. Reynolds and C. L. Beasley, "GABAergic neuronal subtypes in the human frontal cortex-development and deficits in schizophrenia," Journal of Chemical Neuroanatomy, vol. 22, no. 1-2, pp. 95-100, 2001.

[128] M. D. C. Simpson, P. Slater, J. F. W. Deakin, M. C. Royston, and W. J. Skan, "Reduced GABA uptake sites in the temporal lobe in schizophrenia," Neuroscience Letters, vol. 107, no. 1-3, pp. 211$215,1989$.

[129] D. W. Volk, M. C. Austin, J. N. Pierri, A. R. Sampson, and D. A. Lewis, "GABA transporter-1 mRNA in the prefrontal cortex in schizophrenia: decreased expression in a subset of neurons," American Journal of Psychiatry, vol. 158, no. 2, pp. 256-265, 2001.

[130] T.-U. W. Woo, K. Shrestha, C. Amstrong, M. M. Minns, J. P. Walsh, and F. M. Benes, "Differential alterations of kainate receptor subunits in inhibitory interneurons in the anterior cingulate cortex in schizophrenia and bipolar disorder," Schizophrenia Research, vol. 96, no. 1-3, pp. 46-61, 2007.

[131] T.-U. W. Woo, K. Shrestha, D. Lamb, M. M. Minns, and F. M. Benes, "N-methyl-D-aspartate receptor and calbindincontaining neurons in the anterior cingulate cortex in schizophrenia and bipolar disorder," Biological Psychiatry, vol. 64, no. 9, pp. 803-809, 2008.

[132] G. Gonzalez-Burgos, R. Y. Cho, and D. A. Lewis, "Alterations in cortical network oscillations and parvalbumin neurons in schizophrenia," Biological Psychiatry, vol. 77, no. 12, pp. 10311040, 2015.

[133] J. R. Glausier, K. N. Fish, and D. A. Lewis, "Altered parvalbumin basket cell inputs in the dorsolateral prefrontal cortex of schizophrenia subjects," Molecular Psychiatry, vol. 19, no. 1, pp. 30-36, 2014.
[134] M. Laruelle, "Schizophrenia: from dopaminergic to glutamatergic interventions," Current Opinion in Pharmacology, vol. 14, no. 1, pp. 97-102, 2014.

[135] J. W. Olney and N. B. Farber, "Glutamate receptor dysfunction and schizophrenia," Archives of General Psychiatry, vol. 52, no. 12, pp. 998-1007, 1995.

[136] C. A. Tamminga, "Schizophrenia and glutamatergic transmission," Critical Reviews in Neurobiology, vol. 12, no. 1-2, pp. 21-36, 1998.

[137] D. C. Goff and J. T. Coyle, "The emerging role of glutamate in the pathophysiology and treatment of schizophrenia," The American Journal of Psychiatry, vol. 158, no. 9, pp. 1367-1377, 2001.

[138] J. T. Coyle, "The glutamatergic dysfunction hypothesis for schizophrenia," Harvard Review of Psychiatry, vol. 3, no. 5, pp. 241-253, 1996.

[139] J. T. Coyle, "NMDA receptor and schizophrenia: a brief history," Schizophrenia Bulletin, vol. 38, no. 5, pp. 920-926, 2012.

[140] M. Beneyto, L. V. Kristiansen, A. Oni-Orisan, R. E. McCullumsmith, and J. H. Meador-Woodruff, "Abnormal glutamate receptor expression in the medial temporal lobe in schizophrenia and mood disorders," Neuropsychopharmacology, vol. 32, no. 9, pp. 1888-1902, 2007.

[141] M. D. Rubio, J. B. Drummond, and J. H. Meador-Woodruff, "Glutamate receptor abnormalities in schizophrenia: implications for innovative treatments," Biomolecules \& Therapeutics, vol. 20, no. 1, pp. 1-18, 2012.

[142] C. S. Weickert, S. J. Fung, V. S. Catts et al., "Molecular evidence of $N$-methyl-D-aspartate receptor hypofunction in schizophrenia," Molecular Psychiatry, vol. 18, no. 11, pp. 11851192, 2013.

[143] R. Schwarcz, A. Rassoulpour, H.-Q. Wu, D. Medoff, C. A. Tamminga, and R. C. Roberts, "Increased cortical kynurenate content in schizophrenia," Biological Psychiatry, vol. 50, no. 7, pp. 521-530, 2001.

[144] I. Bendikov, C. Nadri, S. Amar et al., "A CSF and postmortem brain study of d-serine metabolic parameters in schizophrenia," Schizophrenia Research, vol. 90, no. 1-3, pp. 41-51, 2007.

[145] S. Erhardt, K. Blennow, C. Nordin, E. Skogh, L. H. Lindstrom, and G. Engberg, "Kynurenic acid levels are elevated in the cerebrospinal fluid of patients with schizophrenia," Neuroscience Letters, vol. 313, pp. 96-98, 2001.

[146] A. Y. Goltsov, J. G. Loseva, T. V. Andreeva et al., "Polymorphism in the $5^{\prime}$-promoter region of serine racemase gene in schizophrenia," Molecular Psychiatry, vol. 11, no. 4, pp. 325-326, 2006.

[147] K. Hashimoto, G. Engberg, E. Shimizu, C. Nordin, L. H. Lindström, and M. Iyo, "Reduced D-serine to total serine ratio in the cerebrospinal fluid of drug naive schizophrenic patients," Progress in Neuro-Psychopharmacology and Biological Psychiatry, vol. 29, no. 5, pp. 767-769, 2005.

[148] V. Labrie, W. Wang, S. W. Barger, G. B. Baker, and J. C. Roder, "Genetic loss of D-amino acid oxidase activity reverses schizophrenia-like phenotypes in mice," Genes, Brain and Behavior, vol. 9, no. 1, pp. 11-25, 2010.

[149] Y. Morita, H. Ujike, Y. Tanaka et al., "A genetic variant of the serine racemase gene is associated with schizophrenia," Biological Psychiatry, vol. 61, no. 10, pp. 1200-1203, 2007.

[150] D. T. Balu and J. T. Coyle, "The NMDA receptor 'glycine modulatory site' in schizophrenia: D-serine, glycine, and beyond," Current Opinion in Pharmacology, vol. 20, pp. 109-115, 2015. 
[151] C. Charrier, P. MacHado, R. Y. Tweedie-Cullen, D. Rutishauser, I. M. Mansuy, and A. Triller, "A crosstalk between $\beta 1$ and $\beta 3$ integrins controls glycine receptor and gephyrin trafficking at synapses," Nature Neuroscience, vol. 13, no. 11, pp. 1388-1395, 2010.

[152] H. Pantazopoulos, N. Lange, L. Hassinger, and S. Berretta, "Subpopulations of neurons expressing parvalbumin in the human amygdala," The Journal of Comparative Neurology, vol. 496, no. 5, pp. 706-722, 2006.

[153] J. M. Ajmo, A. K. Eakin, M. G. Hamel, and P. E. Gottschall, "Discordant localization of WFA reactivity and brevican/ADAMTSderived fragment in rodent brain," BMC Neuroscience, vol. 9, article 14, 2008.

[154] G. Gati and D. Lendvai, "The 'dress' makes the neurondifferent forms of the extracellular matrix in the central nervous system of vertebrates," Orvosi Hetilap, vol. 154, no. 27, pp. 10671073, 1078-1079, 2013.

[155] G. Brückner, K. Brauer, W. Härtig et al., "Perineuronal nets provide a polyanionic, glia-associated form of microenvironment around certain neurons in many parts of the rat brain," Glia, vol. 8, no. 3, pp. 183-200, 1993.

[156] K. Brauer, W. Hartig, J.-M. Fritschy, G. Bruckner, and V. Bigl, "Co-occurrence of perineuronal nets with GABA(A) receptor alphal subunit-immunoreactive neurones in the rat septal region," NeuroReport, vol. 6, no. 5, pp. 733-736, 1995.

[157] W. Härtig, G. Brückner, K. Brauer, C. Schmidt, and V. Bigl, "Allocation of perineuronal nets and parvalbumin-, calbindinD28k- and glutamic acid decarboxylase-immunoreactivity in the amygdala of the rhesus monkey," Brain Research, vol. 698, no. 1-2, pp. 265-269, 1995.

[158] G. Seeger, K. Brauer, W. Härtig, and G. Brückner, "Mapping of perineuronal nets in the rat brain stained by colloidal iron hydroxide histochemistry and lectin cytochemistry," Neuroscience, vol. 58, no. 2, pp. 371-388, 1994.

[159] F. Wegner, W. Härtig, A. Bringmann et al., "Diffuse perineuronal nets and modified pyramidal cells immunoreactive for glutamate and the $\mathrm{GABA}(\mathrm{A})$ receptor alphal subunit form a unique entity in rat cerebral cortex," Experimental Neurology, vol. 184, no. 2, pp. 705-714, 2003.

[160] R. Frischknecht and E. D. Gundelfinger, "The brain's extracellular matrix and its role in synaptic plasticity," in Synaptic Plasticity, vol. 970 of Advances in Experimental Medicine and Biology, pp. 153-171, Springer, Berlin, Germany, 2012.

[161] E. D. Gundelfinger, R. Frischknecht, D. Choquet, and M. Heine, "Converting juvenile into adult plasticity: a role for the brain's extracellular matrix," European Journal of Neuroscience, vol. 31, no. 12, pp. 2156-2165, 2010.

[162] R. Frischknecht, M. Heine, D. Perrais, C. I. Seidenbecher, D. Choquet, and E. D. Gundelfinger, "Brain extracellular matrix affects AMPA receptor lateral mobility and short-term synaptic plasticity," Nature Neuroscience, vol. 12, no. 7, pp. 897-904, 2009.

[163] J. Fawcett, "Molecular control of brain plasticity and repair," Progress in Brain Research, vol. 175, pp. 501-509, 2009.

[164] F. Donato, S. B. Rompani, and P. Caroni, "Parvalbuminexpressing basket-cell network plasticity induced by experience regulates adult learning," Nature, vol. 504, no. 7479, pp. 272-276, 2013.

[165] M. Heine, L. Groc, R. Frischknecht et al., "Surface mobility of postsynaptic AMPARs tunes synaptic transmission," Science, vol. 320 , no. 5873 , pp. 201-205, 2008.
[166] A. Dityatev, G. Brückner, G. Dityateva, J. Grosche, R. Kleene, and M. Schachner, "Activity-dependent formation and functions of chondroitin sulfate-rich extracellular matrix of perineuronal nets," Developmental Neurobiology, vol. 67, no. 5, pp. 570588, 2007.

[167] K. A. Giamanco and R. T. Matthews, "Deconstructing the perineuronal net: cellular contributions and molecular composition of the neuronal extracellular matrix," Neuroscience, vol. 218, pp. 367-384, 2012.

[168] K. A. Giamanco, M. Morawski, and R. T. Matthews, "Perineuronal net formation and structure in aggrecan knockout mice," Neuroscience, vol. 170, no. 4, pp. 1314-1327, 2010.

[169] S. S. Deepa, D. Carulli, C. Galtrey et al., "Composition of perineuronal net extracellular matrix in rat brain: a different disaccharide composition for the net-associated proteoglycans," The Journal of Biological Chemistry, vol. 281, no. 26, pp. 1778917800, 2006.

[170] B. Gaál, S. Kecskes, C. Matesz, A. Birinyi, A. Hunyadi, and É. Rácz, "Molecular composition and expression pattern of the extracellular matrix in a mossy fiber-generating precerebellar nucleus of rat, the prepositus hypoglossi," Neuroscience Letters, vol. 594, pp. 122-126, 2015.

[171] C. Jäger, D. Lendvai, G. Seeger et al., "Perineuronal and perisynaptic extracellular matrix in the human spinal cord," Neuroscience, vol. 238, pp. 168-184, 2013.

[172] D. Lendvai, M. Morawski, L. Négyessy et al., "Neurochemical mapping of the human hippocampus reveals perisynaptic matrix around functional synapses in Alzheimer's disease," Acta Neuropathologica, vol. 125, no. 2, pp. 215-229, 2013.

[173] D. Lendvai, M. Morawski, G. Brückner et al., "Perisynaptic aggrecan-based extracellular matrix coats in the human lateral geniculate body devoid of perineuronal nets," Journal of Neuroscience Research, vol. 90, no. 2, pp. 376-387, 2012.

[174] G. Gáti, M. Morawski, D. Lendvai et al., "Chondroitin sulphate proteoglycan-based perineuronal net establishment is largely activity-independent in chick visual system," Journal of Chemical Neuroanatomy, vol. 40, no. 3, pp. 243-247, 2010.

[175] O. Bukalo, M. Schachner, and A. Dityatev, "Modification of extracellular matrix by enzymatic removal of chondroitin sulfate and by lack of tenascin-R differentially affects several forms of synaptic plasticity in the hippocampus," Neuroscience, vol. 104, no. 2, pp. 359-369, 2001.

[176] S. Miyata, Y. Komatsu, Y. Yoshimura, C. Taya, and H. Kitagawa, "Persistent cortical plasticity by upregulation of chondroitin 6sulfation," Nature Neuroscience, vol. 15, no. 3, pp. 414-422, 2012.

[177] C. Brakebusch, C. I. Seidenbecher, F. Asztely et al., "Brevicandeficient mice display impaired hippocampal CA1 long-term potentiation but show no obvious deficits in learning and memory," Molecular and Cellular Biology, vol. 22, no. 21, pp. 7417-7427, 2002

[178] X.-H. Zhou, C. Brakebusch, H. Matthies et al., "Neurocan is dispensable for brain development," Molecular and Cellular Biology, vol. 21, no. 17, pp. 5970-5978, 2001.

[179] S. R. Saroja, A. Sase, S. G. Kircher et al., "Hippocampal proteoglycans brevican and versican are linked to spatial memory of Sprague-Dawley rats in the morris water maze," Journal of Neurochemistry, vol. 130, no. 6, pp. 797-804, 2014.

[180] G. C. Campo, M. Sinagra, D. Verrier, O. J. Manzoni, and P. Chavis, "Reelin secreted by GABAergic neurons regulates glutamate receptor homeostasis," PLoS ONE, vol. 4, no. 5, Article ID e5505, 2009. 
[181] P. N. Lacor, D. R. Grayson, J. Auta, I. Sugaya, E. Costa, and A. Guidotti, "Reelin secretion from glutamatergic neurons in culture is independent from neurotransmitter regulation," Proceedings of the National Academy of Sciences of the United States of America, vol. 97, no. 7, pp. 3556-3561, 2000.

[182] C. Pesold, F. Impagnatiello, M. O. Pisu et al., "Reelin is preferentially expressed in neurons synthesizing $\gamma$-aminobutyric acid in cortex and hippocampus of adult rats," Proceedings of the National Academy of Sciences of the United States of America, vol. 95, no. 6, pp. 3221-3226, 1998.

[183] G. D’Arcangelo, R. Homayouni, L. Keshvara, D. S. Rice, M. Sheldon, and T. Curran, "Reelin is a ligand for lipoprotein receptors," Neuron, vol. 24, no. 2, pp. 471-479, 1999.

[184] J. Herz and Y. Chen, "Reelin, lipoprotein receptors and synaptic plasticity," Nature Reviews Neuroscience, vol. 7, no. 11, pp. 850859, 2006.

[185] L. Dulabon, E. C. Olson, M. G. Taglienti et al., "Reelin binds $\alpha 3 \beta 1$ integrin and inhibits neuronal migration," Neuron, vol. 27, no. 1, pp. 33-44, 2000.

[186] Y. Chen, U. Beffert, M. Ertunc et al., "Reelin modulates NMDA receptor activity in cortical neurons," Journal of Neuroscience, vol. 25, no. 36, pp. 8209-8216, 2005.

[187] E. Förster, H. H. Bock, J. Herz, X. Chai, M. Frotscher, and S. Zhao, "Emerging topics in Reelin function," European Journal of Neuroscience, vol. 31, no. 9, pp. 1511-1518, 2010.

[188] S. Qiu, L. F. Zhao, K. M. Korwek, and E. J. Weeber, "Differential reelin-induced enhancement of NMDA and AMPA receptor activity in the adult hippocampus," Journal of Neuroscience, vol. 26, no. 50, pp. 12943-12955, 2006.

[189] A. B. McGeachie, L. A. Cingolani, and Y. Goda, "A stabilising influence: integrins in regulation of synaptic plasticity," Neuroscience Research, vol. 70, no. 1, pp. 24-29, 2011.

[190] A. H. Babayan, E. A. Kramár, R. M. Barrett et al., "Integrin dynamics produce a delayed stage of long-term potentiation and memory consolidation," The Journal of Neuroscience, vol. 32, no. 37, pp. 12854-12861, 2012.

[191] C.-S. Chan, H. Chen, A. Bradley, I. Dragatsis, C. Rosenmund, and R. L. Davis, " $\alpha 8$-integrins are required for hippocampal long-term potentiation but not for hippocampal-dependent learning," Genes, Brain and Behavior, vol. 9, no. 4, pp. 402-410, 2010.

[192] A. Dityatev, M. Schachner, and P. Sonderegger, "The dual role of the extracellular matrix in synaptic plasticity and homeostasis," Nature Reviews Neuroscience, vol. 11, no. 11, pp. 735-746, 2010.

[193] K. Pozo and Y. Goda, "Unraveling mechanisms of homeostatic synaptic plasticity," Neuron, vol. 66, no. 3, pp. 337-351, 2010.

[194] G.-M. Sia, J.-C. Béique, G. Rumbaugh, R. Cho, P. F. Worley, and R. L. Huganir, "Interaction of the $\mathrm{N}$-terminal domain of the AMPA receptor GluR4 subunit with the neuronal pentraxin NP1 mediates GluR4 synaptic recruitment," Neuron, vol. 55, no. 1, pp. 87-102, 2007.

[195] M. C. Chang, J. M. Park, K. A. Pelkey et al., "Narp regulates homeostatic scaling of excitatory synapses on parvalbuminexpressing interneurons," Nature Neuroscience, vol. 13, no. 9, pp. 1090-1097, 2010.

[196] S. Kimoto, M. M. Zaki, H. H. Bazmi, and D. A. Lewis, "Altered markers of cortical $\gamma$-aminobutyric acid neuronal activity in schizophrenia: role of the NARP gene," JAMA Psychiatry, vol. 72, no. 8, pp. 747-756, 2015.

[197] A. D. Levy, M. H. Omar, and A. J. Koleske, "Extracellular matrix control of dendritic spine and synapse structure and plasticity in adulthood," Frontiers in Neuroanatomy, vol. 8, article 116, 2014.
[198] R. Madani, S. Hulo, N. Toni et al., "Enhanced hippocampal long-term potentiation and learning by increased neuronal expression of tissue-type plasminogen activator in transgenic mice," The EMBO Journal, vol. 18, no. 11, pp. 3007-3012, 1999.

[199] O. Nicole, F. Docagne, C. Ali et al., "The proteolytic activity of tissue-plasminogen activator enhances NMDA receptormediated signaling," Nature Medicine, vol. 7, no. 1, pp. 59-64, 2001.

[200] P. T. Pang, H. K. Teng, E. Zaitsev et al., "Cleavage of proBDNF by tPA/plasmin is essential for long-term hippocampal plasticity," Science, vol. 306, no. 5695, pp. 487-491, 2004.

[201] S. Hoirisch-Clapauch and A. Nardi, "Multiple roles of tissue plasminogen activator in schizophrenia pathophysiology," Seminars in Thrombosis and Hemostasis, vol. 39, no. 8, pp. 950-954, 2013.

[202] S. Hoirisch-Clapauch and A. E. Nardi, "Markers of low activity of tissue plasminogen activator/plasmin are prevalent in schizophrenia patients," Schizophrenia Research, vol. 159, no. 1, pp. 118-123, 2014.

[203] S. Hoirisch-Clapauch and A. E. Nardi, "Low activity of plasminogen activator: a common feature of non-iatrogenic comorbidities of schizophrenia," CNS \& Neurological Disorders-Drug Targets, vol. 14, no. 3, pp. 325-330, 2015.

[204] A.-P. Sappino, R. Madani, J. Huarte et al., "Extracellular proteolysis in the adult murine brain," The Journal of Clinical Investigation, vol. 92, no. 2, pp. 679-685, 1993.

[205] J. E. Lochner, L. S. Honigman, W. F. Grant et al., "Activitydependent release of tissue plasminogen activator from the dendritic spines of hippocampal neurons revealed by live-cell imaging," Journal of Neurobiology, vol. 66, no. 6, pp. 564-577, 2006.

[206] D. Baranes, D. Lederfein, Y.-Y. Huang, M. Chen, C. H. Bailey, and E. R. Kandel, "Tissue plasminogen activator contributes to the late phase of LTP and to synaptic growth in the hippocampal mossy fiber pathway," Neuron, vol. 21, no. 4, pp. 813-825, 1998.

[207] X.-B. Wang, O. Bozdagi, J. S. Nikitczuk, W. Z. Zu, Q. Zhou, and G. W. Huntley, "Extracellular proteolysis by matrix metalloproteinase-9 drives dendritic spine enlargement and long-term potentiation coordinately," Proceedings of the National Academy of Sciences of the United States of America, vol. 105, no. 49, pp. 19520-19525, 2008.

[208] K. Lepeta and L. Kaczmarek, "Matrix metalloproteinase-9 as a novel player in synaptic plasticity and schizophrenia," Schizophrenia Bulletin, vol. 41, no. 5, pp. 1003-1009, 2015.

[209] S. Ripke, C. O’Dushlaine, K. Chambert et al., "Genome-wide association analysis identifies 13 new risk loci for schizophrenia," Nature Genetics, vol. 45, no. 10, pp. 1150-1159, 2013.

[210] K. Chopra, A. Baveja, and A. Kuhad, "MMPs: a novel drug target for schizophrenia," Expert Opinion on Therapeutic Targets, vol. 19, no. 1, pp. 77-85, 2015.

[211] R. A. Sweet, R. A. Henteleff, W. Zhang, A. R. Sampson, and D. A. Lewis, "Reduced dendritic spine density in auditory cortex of subjects with schizophrenia," Neuropsychopharmacology, vol. 34, no. 2, pp. 374-389, 2009.

[212] K. M. Harris and J. K. Stevens, "Dendritic spines of CA1 pyramidal cells in the rat hippocampus: serial electron microscopy with reference to their biophysical characteristics," Journal of Neuroscience, vol. 9, no. 8, pp. 2982-2997, 1989.

[213] M. B. Kennedy, "The biochemistry of synaptic regulation in the central nervous system," Annual Review of Biochemistry, vol. 63, pp. 571-600, 1994. 
[214] M. B. Kennedy, "The postsynaptic density at glutamatergic synapses," Trends in Neurosciences, vol. 20, no. 6, pp. 264-268, 1997.

[215] C. A. Hunt, L. J. Schenker, and M. B. Kennedy, "PSD-95 is associated with the postsynaptic density and not with the presynaptic membrane at forebrain synapses," The Journal of Neuroscience, vol. 16, no. 4, pp. 1380-1388, 1996.

[216] R. S. Walikonis, O. N. Jensen, M. Mann, D. W. Provance Jr., J. A. Mercer, and M. B. Kennedy, "Identification of proteins in the postsynaptic density fraction by mass spectrometry," The Journal of Neuroscience, vol. 20, no. 11, pp. 4069-4080, 2000.

[217] M. Sheng and E. Kim, "The postsynaptic organization of synapses," Cold Spring Harbor Perspectives in Biology, vol. 3, no. $12,2011$.

[218] K. M. Harris and R. J. Weinberg, "Ultrastructure of synapses in the mammalian brain," Cold Spring Harbor Perspectives in Biology, vol. 4, no. 5, Article ID a005587, 2012.

[219] D. L. Benson and G. W. Huntley, "Synapse adhesion: a dynamic equilibrium conferring stability and flexibility," Current Opinion in Neurobiology, vol. 22, no. 3, pp. 397-404, 2012.

[220] G. W. Huntley, O. Gil, and O. Bozdagi, “The Cadherin family of cell adhesion molecules: multiple roles in synaptic plasticity," Neuroscientist, vol. 8, no. 3, pp. 221-233, 2002.

[221] P. Washbourne, A. Dityatev, P. Scheiffele et al., "Cell adhesion molecules in synapse formation," The Journal of Neuroscience, vol. 24, no. 42, pp. 9244-9249, 2004.

[222] Y. C. Lin and A. J. Koleske, "Mechanisms of synapse and dendrite maintenance and their disruption in psychiatric and neurodegenerative disorders," Annual Review of Neuroscience, vol. 33, no. 1, pp. 349-378, 2010.

[223] L. Cheadle and T. Biederer, "The novel synaptogenic protein farp1 links postsynaptic cytoskeletal dynamics and transsynaptic organization," Journal of Cell Biology, vol. 199, no. 6, pp. 9851001, 2012.

[224] S. Sloniowski and I. M. Ethell, "Looking forward to EphB signaling in synapses," Seminars in Cell and Developmental Biology, vol. 23, no. 1, pp. 75-82, 2012.

[225] A. J. Koleske, "Molecular mechanisms of dendrite stability," Nature Reviews Neuroscience, vol. 14, no. 8, pp. 536-550, 2013.

[226] K. M. Harris and J. K. Stevens, "Dendritic spines of rat cerebellar Purkinje cells: serial electron microscopy with reference to their biophysical characteristics," The Journal of Neuroscience, vol. 8, no. 12 , pp. 4455-4469, 1988.

[227] M. Matsuzaki, G. C. R. Ellis-Davies, T. Nemoto, Y. Miyashita, M. Iino, and H. Kasai, "Dendritic spine geometry is critical for AMPA receptor expression in hippocampal CA1 pyramidal neurons," Nature Neuroscience, vol. 4, no. 11, pp. 1086-1092, 2001.

[228] M. Matsuzaki, N. Honkura, G. C. R. Ellis-Davies, and H. Kasai, "Structural basis of long-term potentiation in single dendritic spines," Nature, vol. 429, no. 6993, pp. 761-766, 2004.

[229] U. V. Nägerl, N. Eberhorn, S. B. Cambridge, and T. Bonhoeffer, "Bidirectional activity-dependent morphological plasticity in hippocampal neurons," Neuron, vol. 44, no. 5, pp. 759-767, 2004.

[230] Q. Zhou, K. J. Homma, and M.-M. Poo, "Shrinkage of dendritic spines associated with long-term depression of hippocampal synapses," Neuron, vol. 44, no. 5, pp. 749-757, 2004.

[231] W. C. Oh, T. C. Hill, and K. Zito, "Synapse-specific and sizedependent mechanisms of spine structural plasticity accompanying synaptic weakening," Proceedings of the National Academy of Sciences of the United States of America, vol. 110, no. 4, pp. E305-E312, 2013.
[232] N. Bastrikova, G. A. Gardner, J. M. Reece, A. Jeromin, and S. M. Dudek, "Synapse elimination accompanies functional plasticity in hippocampal neurons," Proceedings of the National Academy of Sciences of the United States of America, vol. 105, no. 8, pp. 3123-3127, 2008.

[233] T. Pizzorusso, P. Medini, S. Landi, S. Baldini, N. Berardi, and L. Maffei, "Structural and functional recovery from early monocular deprivation in adult rats," Proceedings of the National Academy of Sciences of the United States of America, vol. 103, no. 22, pp. 8517-8522, 2006.

[234] A. Majewska and M. Sur, "Motility of dendritic spines in visual cortex in vivo: changes during the critical period and effects of visual deprivation," Proceedings of the National Academy of Sciences of the United States of America, vol. 100, no. 26, pp. 16024-16029, 2003.

[235] L. de Vivo, S. Landi, M. Panniello et al., "Extracellular matrix inhibits structural and functional plasticity of dendritic spines in the adult visual cortex," Nature Communications, vol. 4, article 1484, 2013.

[236] C. Orlando, J. Ster, U. Gerber, J. W. Fawcett, and O. Raineteau, "Perisynaptic chondroitin sulfate proteoglycans restrict structural plasticity in an integrin-dependent manner," The Journal of Neuroscience, vol. 32, no. 50, pp. 18009-18017, 2012.

[237] L. Pujadas, A. Gruart, C. Bosch et al., "Reelin regulates postnatal neurogenesis and enhances spine hypertrophy and long-term potentiation," Journal of Neuroscience, vol. 30, no. 13, pp. 46364649, 2010.

[238] U. Beffert, E. J. Weeber, A. Durudas et al., "Modulation of synaptic plasticity and memory by Reelin involves differential splicing of the lipoprotein receptor Apoer2," Neuron, vol. 47, no. 4, pp. 567-579, 2005.

[239] H. Pribiag, H. Peng, W. A. Shah, D. Stellwagen, and S. Carbonetto, "Dystroglycan mediates homeostatic synaptic plasticity at GABAergic synapses," Proceedings of the National Academy of Sciences of the United States of America, vol. 111, no. 18, pp. 6810-6815, 2014.

[240] J. S. Satz, A. P. Ostendorf, S. Hou et al., "Distinct functions of glial and neuronal dystroglycan in the developing and adult mouse brain," The Journal of Neuroscience, vol. 30, no. 43, pp. 14560-14572, 2010.

[241] U. Beffert, A. Durudas, E. J. Weeber et al., "Functional dissection of Reelin signaling by site-directed disruption of disabled-1 adaptor binding to apolipoprotein E receptor 2: distinct roles in development and synaptic plasticity," Journal of Neuroscience, vol. 26, no. 7, pp. 2041-2052, 2006.

[242] J. H. Trotter, M. Klein, U. K. Jinwal et al., "ApoER2 function in the establishment and maintenance of retinal synaptic connectivity," The Journal of Neuroscience, vol. 31, no. 40, pp. 1441314423, 2011.

[243] E. Costa, J. Davis, D. R. Grayson, A. Guidotti, G. D. Pappas, and C. Pesold, "Dendritic spine hypoplasticity and downregulation of reelin and GABAergic tone in schizophrenia vulnerability," Neurobiology of Disease, vol. 8, no. 5, pp. 723-742, 2001.

[244] S. L. Eastwood and P. J. Harrison, "Cellular basis of reduced cortical reelin expression in schizophrenia," The American Journal of Psychiatry, vol. 163, no. 3, pp. 540-542, 2006.

[245] N. Uesaka, M. Uchigashima, T. Mikuni et al., "Retrograde semaphorin signaling regulates synapse elimination in the developing mouse brain," Science, vol. 344, no. 6187, pp. 1020 1023, 2014.

[246] D. Carulli, S. Foscarin, A. Faralli, E. Pajaj, and F. Rossi, "Modulation of semaphorin3A in perineuronal nets during 
structural plasticity in the adult cerebellum," Molecular and Cellular Neuroscience, vol. 57, pp. 10-22, 2013.

[247] G. Dick, C. L. Tan, J. N. Alves et al., "Semaphorin 3A binds to the perineuronal nets via chondroitin sulfate type E motifs in rodent brains," The Journal of Biological Chemistry, vol. 288, no. 38, pp. 27384-27395, 2013.

[248] T. Vo, D. Carulli, E. M. E. Ehlert et al., "The chemorepulsive axon guidance protein semaphorin $3 \mathrm{~A}$ is a constituent of perineuronal nets in the adult rodent brain," Molecular and Cellular Neuroscience, vol. 56, pp. 186-200, 2013.

[249] R. Pawlak, B. S. S. Rao, J. P. Melchor, S. Chattarji, B. McEwen, and S. Strickland, "Tissue plasminogen activator and plasminogen mediate stress-induced decline of neuronal and cognitive functions in the mouse hippocampus," Proceedings of the National Academy of Sciences of the United States of America, vol. 102, no. 50, pp. 18201-18206, 2005.

[250] S. Bennur, B. S. Shankaranarayana Rao, R. Pawlak, S. Strickland, B. S. McEwen, and S. Chattarji, "Stress-induced spine loss in the medial amygdala is mediated by tissue-plasminogen activator," Neuroscience, vol. 144, no. 1, pp. 8-16, 2007.

[251] P. Michaluk, M. Wawrzyniak, P. Alot et al., "Influence of matrix metalloproteinase MMP-9 on dendritic spine morphology," Journal of Cell Science, vol. 124, no. 19, pp. 3369-3380, 2011.

[252] T. V. Bilousova, D. A. Rusakov, D. W. Ethell, and I. M. Ethell, "Matrix metalloproteinase-7 disrupts dendritic spines in hippocampal neurons through NMDA receptor activation," Journal of Neurochemistry, vol. 97, no. 1, pp. 44-56, 2006.

[253] V. Nagy, O. Bozdagi, A. Matynia et al., "Matrix metalloproteinase- 9 is required for hippocampal late-phase long-term potentiation and memory," The Journal of Neuroscience, vol. 26, no. 7, pp. 1923-1934, 2006.

[254] K. Tsamis, D. Mytilinaios, D. Psaroulis, S. N. Njau, V. Costa, and S. J. Baloyannis, "Reelin immunoreactivity and morphological analysis of the human visual cortex," International Journal of Neuroscience, vol. 117, no. 1, pp. 25-46, 2007.

[255] J. Spatazza, H. H. C. Lee, A. A. DiNardo et al., "Choroid-plexusderived otx2 homeoprotein constrains adult cortical plasticity," Cell Reports, vol. 3, no. 6, pp. 1815-1823, 2013.

[256] M. Beurdeley, J. Spatazza, H. H. C. Lee et al., "Otx2 binding to perineuronal nets persistently regulates plasticity in the mature visual cortex," Journal of Neuroscience, vol. 32, no. 27, pp. 94299437, 2012.

[257] G. Poelmans, B. Franke, D. L. Pauls, J. C. Glennon, and J. K. Buitelaar, "AKAPs integrate genetic findings for autism spectrum disorders," Translational Psychiatry, vol. 3, article e270, 2013.

[258] D. Ma, D. Salyakina, J. M. Jaworski et al., "A genome-wide association study of autism reveals a common novel risk locus at 5p14.1," Annals of Human Genetics, vol. 73, no. 3, pp. 263-273, 2009.

[259] K. Wang, H. Zhang, D. Ma et al., "Common genetic variants on 5 p14.1 associate with autism spectrum disorders," Nature, vol. 459, no. 7246, pp. 528-533, 2009.

[260] L. A. Weiss, D. E. Arking, M. J. Daly, and A. Chakravarti, "A genome-wide linkage and association scan reveals novel loci for autism," Nature, vol. 461, no. 7265, pp. 802-808, 2009.

[261] D. Salyakina, D. Q. Ma, J. M. Jaworski et al., "Variants in several genomic regions associated with asperger disorder," Autism Research, vol. 3, no. 6, pp. 303-310, 2010.
[262] J. P. Hussman, R.-H. Chung, A. J. Griswold et al., "A noisereduction GWAS analysis implicates altered regulation of neurite outgrowth and guidance in Autism," Molecular Autism, vol. 2, article 1, 2011.

[263] R. Anney, L. Klei, D. Pinto et al., "A genome-wide scan for common alleles affecting risk for autism," Human Molecular Genetics, vol. 19, no. 20, pp. 4072-1082, 2010.

[264] A. M. Persico, L. D’agruma, N. Maiorano et al., "Reelin gene alleles and haplotypes as a factor predisposing to autistic disorder," Molecular Psychiatry, vol. 6, no. 2, pp. 150-159, 2001.

[265] S. H. Fatemi, "The role of Reelin in pathology of autism," Molecular Psychiatry, vol. 7, no. 9, pp. 919-920, 2002.

[266] H. Zhang, X. Liu, C. Zhang et al., "Reelin gene alleles and susceptibility to autism spectrum disorders," Molecular Psychiatry, vol. 7, no. 9, pp. 1012-1017, 2002.

[267] C. W. Bartlett, N. Gharani, J. H. Millonig, and L. M. Brzustowicz, "Three autism candidate genes: a synthesis of human genetic analysis with other disciplines," International Journal of Developmental Neuroscience, vol. 23, no. 2-3, pp. 221-234, 2005.

[268] D. A. Skaar, Y. Shao, J. L. Haines et al., "Analysis of the RELN gene as a genetic risk factor for autism," Molecular Psychiatry, vol. 10, no. 6, pp. 563-571, 2005.

[269] F. J. Serajee, H. Zhong, and A. H. M. Mahbubul Huq, "Association of Reelin gene polymorphisms with autism," Genomics, vol. 87, no. 1, pp. 75-83, 2006.

[270] H. Li, Y. Li, J. Shao et al., "The association analysis of RELN and GRM8 genes with autistic spectrum disorder in Chinese Han population," American Journal of Medical Genetics, Part B: Neuropsychiatric Genetics, vol. 147, no. 2, pp. 194-200, 2008.

[271] X. Li, H. Zou, and W. T. Brown, "Genes associated with autism spectrum disorder," Brain Research Bulletin, vol. 88, no. 6, pp. 543-552, 2012.

[272] Z. Wang, Y. Hong, L. Zou et al., "Reelin gene variants and risk of autism spectrum disorders: an integrated meta-analysis," American Journal of Medical Genetics, Part B: Neuropsychiatric Genetics, vol. 165, no. 2, pp. 192-200, 2014.

[273] S. H. Fatemi, J. M. Stary, A. R. Halt, and G. R. Realmuto, "Dysregulation of Reelin and Bcl-2 proteins in autistic cerebellum," Journal of Autism and Developmental Disorders, vol. 31, no. 6, pp. 529-535, 2001.

[274] S. H. Fatemi, A. V. Snow, J. M. Stary et al., "Reelin signaling is impaired in autism," Biological Psychiatry, vol. 57, no. 7, pp. 777787, 2005.

[275] S. H. Fatemi, "Reelin glycoprotein in autism and schizophrenia," International Review of Neurobiology, vol. 71, pp. 179-187, 2005.

[276] B. L. Pearson, M. J. Corley, A. Vasconcellos, D. C. Blanchard, and R. J. Blanchard, "Heparan sulfate deficiency in autistic postmortem brain tissue from the subventricular zone of the lateral ventricles," Behavioural Brain Research, vol. 243, no. 1, pp. 138-145, 2013.

[277] K. Z. Meyza, D. C. Blanchard, B. L. Pearson, R. L. H. Pobbe, and R. J. Blanchard, "Fractone-associated N-sulfated heparan sulfate shows reduced quantity in BTBR T+tf/J mice: a strong model of autism," Behavioural Brain Research, vol. 228, no. 2, pp. 247-253, 2012.

[278] F. Mercier, Y. C. Kwon, and V. Douet, "Hippocampus/amygdala alterations, loss of heparan sulfates, fractones and ventricle wall reduction in adult BTBR $\mathrm{T}+\mathrm{tf} / \mathrm{J}$ mice, animal model for autism," Neuroscience Letters, vol. 506, no. 2, pp. 208-213, 2012.

[279] C. M. Schumann and D. G. Amaral, "Stereological analysis of amygdala neuron number in autism," Journal of Neuroscience, vol. 26 , no. 29 , pp. 7674-7679, 2006. 
[280] M. Bauman and T. L. Kemper, "Histoanatomic observations of the brain in early infantile autism," Neurology, vol. 35, no. 6, pp. 866-874, 1985.

[281] F. Irie, H. Badie-Mahdavi, and Y. Yamaguchi, "Autism-like socio-communicative deficits and stereotypies in mice lacking heparan sulfate," Proceedings of the National Academy of Sciences of the United States of America, vol. 109, no. 13, pp. 5052-5056, 2012.

[282] C. Gillberg and E. Billstedt, "Autism and Asperger syndrome: coexistence with other clinical disorders," Acta Psychiatrica Scandinavica, vol. 102, no. 5, pp. 321-330, 2000.

[283] J. Wahlstrom, C. Gillberg, K.-H. Gustavson, and G. Holmgren, "Infantile autism and the fragile X. A Swedish multicenter study," American Journal of Medical Genetics, vol. 23, no. 1-2, pp. 403-408, 1986.

[284] C. Gillberg, "Identical triplets with infantile autism and the fragile-X syndrome," British Journal of Psychiatry, vol. 143, no. 3, pp. 256-260, 1983.

[285] W. T. O'Donnell and S. T. Warren, "A decade of molecular studies of fragile X syndrome," Annual Review of Neuroscience, vol. 25, pp. 315-338, 2002.

[286] L. N. Antar, R. Afroz, J. B. Dictenberg, R. C. Carroll, and G. J. Bassell, "Metabotropic glutamate receptor activation regulates fragile $\mathrm{x}$ mental retardation protein and FMR1 mRNA localization differentially in dendrites and at synapses," The Journal of Neuroscience, vol. 24, no. 11, pp. 2648-2655, 2004.

[287] J. C. Darnell, S. J. Van Driesche, C. Zhang et al., "FMRP stalls ribosomal translocation on mRNAs linked to synaptic function and autism," Cell, vol. 146, no. 2, pp. 247-261, 2011.

[288] S. A. Irwin, R. Galvez, and W. T. Greenough, "Dendritic spine structural anomalies in fragile-X mental retardation syndrome," Cerebral Cortex, vol. 10, no. 10, pp. 1038-1044, 2000.

[289] S. A. Irwin, B. Patel, M. Idupulapati et al., "Abnormal dendritic spine characteristics in the temporal and visual cortices of patients with fragile-X syndrome: a quantitative examination," American Journal of Medical Genetics, vol. 98, no. 2, pp. 161-167, 2001.

[290] R. Lu, H. Wang, Z. Liang et al., "The fragile X protein controls microtubule-associated protein $1 \mathrm{~B}$ translation and microtubule stability in brain neuron development," Proceedings of the National Academy of Sciences of the United States of America, vol. 101, no. 42, pp. 15201-15206, 2004.

[291] R. S. Muddashetty, S. Kelić, C. Gross, M. Xu, and G. J. Bassell, "Dysregulated metabotropic glutamate receptordependent translation of AMPA receptor and postsynaptic density-95 mRNAs at synapses in a mouse model of fragile $\mathrm{X}$ syndrome," The Journal of Neuroscience, vol. 27, no. 20, pp. 53385348, 2007.

[292] F. Zalfa, M. Giorgi, B. Primerano et al., "The Fragile X syndrome protein FMRP associates with $\mathrm{BCl}$ RNA and regulates the translation of specific mRNAs at synapses," Cell, vol. 112, no. 3, pp. 317-327, 2003.

[293] R. D. Rudelli, W. T. Brown, K. Wisniewski, E. C. Jenkins, M. Laure-Kamionowska, and F. Connell, "Adult fragile X syndrome. Clinico-neuropathologic findings," Acta Neuropathologica, vol. 67, no. 3-4, pp. 289-295, 1985.

[294] P. Michaluk, L. Kolodziej, B. Mioduszewska et al., "Betadystroglycan as a target for MMP-9, in response to enhanced neuronal activity," The Journal of Biological Chemistry, vol. 282, no. 22, pp. 16036-16041, 2007.

[295] A. Janusz, J. Miłek, M. Perycz et al., “The Fragile X mental retardation protein regulates matrix metalloproteinase $9 \mathrm{mRNA}$ at synapses," Journal of Neuroscience, vol. 33, no. 46, pp. 1823418241, 2013.

[296] M. Dziembowska, D. I. Pretto, A. Janusz et al., "High MMP-9 activity levels in fragile $\mathrm{X}$ syndrome are lowered by minocycline," American Journal of Medical Genetics Part A, vol. 161, no. 8, pp. 1897-1903, 2013.

[297] M. W. Abdallah, B. D. Pearce, N. Larsen et al., "Amniotic fluid MMP-9 and neurotrophins in autism spectrum disorders: an exploratory study," Autism Research, vol. 5, no. 6, pp. 428-433, 2012.

[298] E. A. Nimchinsky, A. M. Oberlander, and K. Svoboda, "Abnormal development of dendritic spines in FMR1 knock-out mice," The Journal of Neuroscience, vol. 21, no. 14, pp. 5139-5146, 2001.

[299] T. V. Bilousova, L. Dansie, M. Ngo et al., "Minocycline promotes dendritic spine maturation and improves behavioural performance in the fragile X mouse model," Journal of Medical Genetics, vol. 46, no. 2, pp. 94-102, 2009.

[300] H. Sidhu, L. E. Dansie, P. W. Hickmott, D. W. Ethell, and I. M. Ethell, "Genetic removal of matrix metalloproteinase 9 rescues the symptoms of fragile $\mathrm{X}$ syndrome in a mouse model," The Journal of Neuroscience, vol. 34, no. 30, pp. 9867-9879, 2014.

[301] M. Chahrour and H. Y. Zoghbi, “The story of Rett syndrome: from clinic to neurobiology," Neuron, vol. 56, no. 3, pp. 422-437, 2007.

[302] P. Moretti, J. M. Levenson, F. Battaglia et al., "Learning and memory and synaptic plasticity are impaired in a mouse model of Rett syndrome," Journal of Neuroscience, vol. 26, no. 1, pp. 319327, 2006.

[303] C. A. Chapleau, G. D. Calfa, M. C. Lane et al., "Dendritic spine pathologies in hippocampal pyramidal neurons from Rett syndrome brain and after expression of Rett-associated MECP2 mutations," Neurobiology of Disease, vol. 35, no. 2, pp. 219-233, 2009.

[304] S.-M. Weng, M. E. S. Bailey, and S. R. Cobb, "Rett syndrome: from bed to bench," Pediatrics and Neonatology, vol. 52, no. 6, pp. 309-316, 2011.

[305] M. V. C. Nguyen, F. Du, C. A. Felice et al., "MeCP2 is critical for maintaining mature neuronal networks and global brain anatomy during late stages of postnatal brain development and in the mature adult brain," The Journal of Neuroscience, vol. 32, no. 29, pp. 10021-10034, 2012.

[306] G. Della Sala and T. Pizzorusso, "Synaptic plasticity and signaling in Rett syndrome," Developmental Neurobiology, vol. 74, no. 2, pp. 178-196, 2014.

[307] R. E. Amir, I. B. Van Den Veyver, M. Wan, C. Q. Tran, U. Francke, and H. Y. Zoghbi, "Rett syndrome is caused by mutations in X-linked MECP2, encoding methyl-CpG-binding protein 2," Nature Genetics, vol. 23, no. 2, pp. 185-188, 1999.

[308] L. Colvin, H. Leonard, N. de Klerk et al., "Refining the phenotype of common mutations in Rett syndrome," Journal of Medical Genetics, vol. 41, no. 1, pp. 25-30, 2004.

[309] C. R. Jordan, H. H. Li, H. C. Kwan, and U. Francke, "Cerebellar gene expression profiles of mouse models for Rett syndrome reveal novel MeCP2 targets," BMC Medical Genetics, vol. 8, article 36, 2007.

[310] P. V. Belichenko, B. Hagberg, and A. Dahlström, "Morphological study of neocortical areas in Rett syndrome," Acta Neuropathologica, vol. 93, no. 1, pp. 50-61, 1997.

[311] S. H. Fatemi, J. A. Earle, and T. McMenomy, "Reduction in Reelin immunoreactivity in hippocampus of subjects with schizophrenia, bipolar disorder and major depression," Molecular Psychiatry, vol. 5, no. 6, pp. 654-663, 2000. 
[312] S. H. Fatemi, J. M. Stary, J. A. Earle, M. Araghi-Niknam, and E. Eagan, "GABAergic dysfunction in schizophrenia and mood disorders as reflected by decreased levels of glutamic acid decarboxylase 65 and $67 \mathrm{kDa}$ and Reelin proteins in cerebellum," Schizophrenia Research, vol. 72, no. 2-3, pp. 109122, 2005.

[313] S. H. Fatemi, J. L. Kroll, and J. M. Stary, "Altered levels of Reelin and its isoforms in schizophrenia and mood disorders," Neuroreport, vol. 12, no. 15, pp. 3209-3215, 2001.

[314] S. Cichon, T. W. Muhleisen, F. A. Degenhardt et al., "Genomewide association study identifies genetic variation in neurocan as a susceptibility factor for bipolar disorder," The American Journal of Human Genetics, vol. 88, no. 3, pp. 372-381, 2011.

[315] P. Licznerski and R. S. Duman, "Remodeling of axo-spinous synapses in the pathophysiology and treatment of depression," Neuroscience, vol. 251, pp. 33-50, 2013.

[316] A. Guidotti, C. Pesold, and E. Costa, "New neurochemical markers for psychosis: a working hypothesis of their operation," Neurochemical Research, vol. 25, no. 9, pp. 1207-1218, 2000.

[317] S. H. Fatemi, "Reelin glycoprotein: structure, biology and roles in health and disease," Molecular Psychiatry, vol. 10, no. 3, pp. 251-257, 2005.

[318] J. K. Rybakowski, A. Remlinger-Molenda, A. Czech-Kucharska, M. Wojcicka, M. Michalak, and J. Losy, "Increased serum matrix metalloproteinase-9 (MMP-9) levels in young patients during bipolar depression," Journal of Affective Disorders, vol. 146, no. 2, pp. 286-289, 2013.

[319] T. Yoshida, M. Ishikawa, T. Niitsu et al., "Decreased serum levels of mature brain-derived neurotrophic factor (BDNF), but not its precursor proBDNF, in patients with major depressive disorder," PLoS ONE, vol. 7, no. 8, Article ID e42676, 2012.

[320] X. Miró, S. Meier, M. L. Dreisow et al., "Studies in humans and mice implicate neurocan in the etiology of mania," The American Journal of Psychiatry, vol. 169, no. 9, pp. 982-990, 2012.

[321] R. Guirado, M. Perez-Rando, D. Sanchez-Matarredona, E. Castrén, and J. Nacher, "Chronic fluoxetine treatment alters the structure, connectivity and plasticity of cortical interneurons," International Journal of Neuropsychopharmacology, vol. 17, pp. 1635-1646, 2014.

[322] K. Ohira, R. Takeuchi, T. Iwanaga, and T. Miyakawa, "Chronic fluoxetine treatment reduces parvalbumin expression and perineuronal nets in gamma-aminobutyric acidergic interneurons of the frontal cortex in adult mice," Molecular Brain, vol. 6, no. 1, article 43, 2013.

[323] J. Umemori, F. Winkel, E. Castrén, and N. N. Karpova, "Distinct effects of perinatal exposure to fluoxetine or methylmercury on parvalbumin and perineuronal nets, the markers of critical periods in brain development," International Journal of Developmental Neuroscience, vol. 44, pp. 55-64, 2015.

[324] L.-W. Yick, K.-F. So, P.-T. Cheung, and W.-T. Wu, "Lithium chloride reinforces the regeneration-promoting effect of chondroitinase ABC on rubrospinal neurons after spinal cord injury," Journal of Neurotrauma, vol. 21, no. 7, pp. 932-943, 2004.

[325] J. P. Frederick, A. T. Tafari, S.-M. Wu et al., "A role for a lithium-inhibited Golgi nucleotidase in skeletal development and sulfation," Proceedings of the National Academy of Sciences of the United States of America, vol. 105, no. 33, pp. 11605-11612, 2008.

[326] M. Knobloch and I. M. Mansuy, "Dendritic spine loss and synaptic alterations in Alzheimer's disease," Molecular Neurobiology, vol. 37, no. 1, pp. 73-82, 2008.
[327] N. K. Gonatas, "Neocortical synapses in a presenile dementia," Journal of Neuropathology and Experimental Neurology, vol. 26, no. 1, pp. 150-151, 1967.

[328] R. D. Terry, E. Masliah, D. P. Salmon et al., "Physical basis of cognitive alterations in Alzheimer's disease: synapse loss is the major correlate of cognitive impairment," Annals of Neurology, vol. 30, no. 4, pp. 572-580, 1991.

[329] D. Scheuner, C. Eckman, M. Jensen et al., "Secreted amyloid $\beta$-protein similar to that in the senile plaques of Alzheimer's disease is increased in vivo by the presenilin 1 and 2 and APP mutations linked to familial Alzheimer's disease," Nature Medicine, vol. 2, no. 8, pp. 864-870, 1996.

[330] J. Hardy and D. J. Selkoe, "The amyloid hypothesis of Alzheimer's disease: progress and problems on the road to therapeutics," Science, vol. 297, no. 5580, pp. 353-356, 2002.

[331] R. Vassar, B. D. Bennett, S. Babu-Khan et al., “ $\beta$-secretase cleavage of Alzheimer's amyloid precursor protein by the transmembrane aspartic protease BACE," Science, vol. 286, no. 5440, pp. 735-741, 1999.

[332] R. Schwörer, O. V. Zubkova, J. E. Turnbull, and P. C. Tyler, "Synthesis of a targeted library of heparan sulfate hexa- to dodecasaccharides as inhibitors of beta-secretase: potential therapeutics for Alzheimer's disease," Chemistry-A European Journal, vol. 19, no. 21, pp. 6817-6823, 2013.

[333] S. J. Patey, E. A. Edwards, E. A. Yates, and J. E. Turnbull, "Engineered heparins: novel $\beta$-secretase inhibitors as potential Alzheimer's disease therapeutics," Neurodegenerative Diseases, vol. 5, no. 3-4, pp. 197-199, 2008.

[334] Z. Scholefield, E. A. Yates, G. Wayne, A. Amour, W. McDowell, and J. E. Turnbull, "Heparan sulfate regulates amyloid precursor protein processing by BACE1, the Alzheimer's $\beta$-secretase," The Journal of Cell Biology, vol. 163, no. 1, pp. 97-107, 2003.

[335] J. H. Su, B. J. Cummings, and C. W. Cotman, "Localization of heparan sulfate glycosaminoglycan and proteoglycan core protein in aged brain and Alzheimer's disease," Neuroscience, vol. 51, no. 4, pp. 801-813, 1992.

[336] A. D. Snow, R. T. Sekiguchi, D. Nochlin, R. N. Kalaria, and K. Kimata, "Heparan sulfate proteoglycan in diffuse plaques of hippocampus but not of cerebellum in Alzheimer's disease brain," The American Journal of Pathology, vol. 144, no. 2, pp. 337-347, 1994.

[337] N. Watanabe, W. Araki, D.-H. Chui, T. Makifuchi, Y. Ihara, and T. Tabira, "Glypican- 1 as an A $\beta$ binding HSPG in the human brain: Its localization in DIG domains and possible roles in the pathogenesis of Alzheimer's disease," The FASEB Journal, vol. 18, no. 9, pp. 1013-1015, 2004.

[338] I. B. Bruinsma, L. te Riet, T. Gevers et al., "Sulfation of heparan sulfate associated with amyloid- $\beta$ plaques in patients with Alzheimer's disease," Acta Neuropathologica, vol. 119, no. 2, pp. 211-220, 2010.

[339] E. I. Leonova and O. V. Galzitskaya, "Role of syndecan-2 in amyloid plaque formation," Molecular Biology, vol. 49, no. 1, pp. 89-98, 2015.

[340] A. D. Snow, H. Mar, D. Nochlin et al., "The presence of heparan sulfate proteoglycans in the neuritic plaques and congophilic angiopathy in Alzheimer's disease," The American Journal of Pathology, vol. 133, no. 3, pp. 456-463, 1988.

[341] Y.-L. Lin, Y.-T. Lei, C.-J. Hong, and Y.-P. Hsueh, "Syndecan2 induces filopodia and dendritic spine formation via the neurofibromin-PKA-Ena/VASP pathway," The Journal of Cell Biology, vol. 177, no. 5, pp. 829-841, 2007. 
[342] I. M. Ethell, F. Irie, M. S. Kalo, J. R. Couchman, E. B. Pasquale, and Y. Yamaguchi, "EphB/syndecan-2 signaling in dendritic spine morphogenesis," Neuron, vol. 31, no. 6, pp. 1001-1013, 2001.

[343] I. M. Ethell, K. Hagihara, Y. Miura, F. Irie, and Y. Yamaguchi, "Synbindin, a novel syndecan-2-binding protein in neuronal dendritic spines," Journal of Cell Biology, vol. 151, no. 1, pp. 53-67, 2000.

[344] I. M. Ethell and Y. Yamaguchi, "Cell surface heparan sulfate proteoglycan syndecan-2 induces the maturation of dendritic spines in rat hippocampal neurons," Journal of Cell Biology, vol. 144, no. 3, pp. 575-586, 1999.

[345] M. M. Verbeek, I. Otte-Höller, J. van den Born et al., "Agrin is a major heparan sulfate proteoglycan accumulating in Alzheimer's disease brain," The American Journal of Pathology, vol. 155, no. 6, pp. 2115-2125, 1999.

[346] B. Lindahl, L. Eriksson, and U. Lindahl, "Structure of heparan sulphate from human brain, with special regard to Alzheimer's disease," Biochemical Journal, vol. 306, part 1, pp. 177-184, 1995.

[347] D. A. DeWitt, J. Silver, D. R. Canning, and G. Perry, "Chondroitin sulfate proteoglycans are associated with the lesions of Alzheimer's disease," Experimental Neurology, vol. 121, no. 2, pp. 149-152, 1993.

[348] M. N. Pangalos, J. Shioi, and N. K. Robakis, "Expression of the chondroitin sulfate proteoglycans of amyloid precursor (appican) and amyloid precursor-like protein 2," Journal of Neurochemistry, vol. 65, no. 2, pp. 762-769, 1995.

[349] E. Marcello, C. Saraceno, S. Musardo et al., "Endocytosis of synaptic ADAM10 in neuronal plasticity and Alzheimer's disease," Journal of Clinical Investigation, vol. 123, no. 6, pp. 2523-2538, 2013.

[350] H.-S. Hoe, Z. Fu, A. Makarova et al., "The effects of amyloid precursor protein on postsynaptic composition and activity," The Journal of Biological Chemistry, vol. 284, no. 13, pp. 8495$8506,2009$.

[351] A. Fragkouli, E. C. Tsilibary, and A. K. Tzinia, "Neuroprotective role of MMP-9 overexpression in the brain of Alzheimer's 5xFAD mice," Neurobiology of Disease, vol. 70, pp. 179-189, 2014.

[352] A. Fragkouli, A. K. Tzinia, I. Charalampopoulos, A. Gravanis, and E. C. Tsilibary, "Matrix metalloproteinase- 9 participates in NGF-induced $\alpha$-secretase cleavage of amyloid- $\beta$ protein precursor in PC12 cells," Journal of Alzheimer's Disease, vol. 24, no. 4, pp. 705-719, 2011.

[353] J. R. Backstrom, G. P. Lim, M. J. Cullen, and Z. A. Tökés, "Matrix metalloproteinase-9 (MMP-9) is synthesized in neurons of the human hippocampus and is capable of degrading the amyloidbeta peptide (1-40)," The Journal of Neuroscience, vol. 16, no. 24, pp. 7910-7919, 1996.

[354] K.-J. Yin, J. R. Cirrito, P. Yan et al., "Matrix metalloproteinases expressed by astrocytes mediate extracellular amyloid- $\beta$ peptide catabolism," Journal of Neuroscience, vol. 26, no. 43, pp. 10939-10948, 2006.

[355] S. Baig, G. K. Wilcock, and S. Love, "Loss of perineuronal net $N$ acetylgalactosamine in Alzheimer's disease," Acta Neuropathologica, vol. 110, no. 4, pp. 393-401, 2005.

[356] M. Morawski, G. Brückner, C. Jäger, G. Seeger, and T. Arendt, "Neurons associated with aggrecan-based perineuronal nets are protected against tau pathology in subcortical regions in Alzheimer's disease," Neuroscience, vol. 169, no. 3, pp. 1347-1363, 2010.

[357] M. Okamoto, J. Sakiyama, S. Mori et al., "Kainic acid-induced convulsions cause prolonged changes in the chondroitin sulfate proteoglycans neurocan and phosphacan in the limbic structures," Experimental Neurology, vol. 184, no. 1, pp. 179-195, 2003.

[358] E. K. Rankin-Gee, P. A. McRae, E. Baranov, S. Rogers, L. Wandrey, and B. E. Porter, "Perineuronal net degradation in epilepsy," Epilepsia, vol. 56, no. 7, pp. 1124-1133, 2015.

[359] M. Wennström, J. Hellsten, and A. Tingström, "Electroconvulsive seizures induce proliferation of NG2-expressing glial cells in adult rat amygdala," Biological Psychiatry, vol. 55, no. 5, pp. 464-471, 2004.

[360] M. Wennström, J. Hellsten, C. T. Ekdahl, and A. Tingström, "Electroconvulsive seizures induce proliferation of NG2expressing glial cells in adult rat hippocampus," Biological Psychiatry, vol. 54, no. 10, pp. 1015-1024, 2003.

[361] F. Matsui, S. Kawashima, T. Shuo et al., "Transient expression of juvenile-type neurocan by reactive astrocytes in adult rat brains injured by kainate-induced seizures as well as surgical incision," Neuroscience, vol. 112, no. 4, pp. 773-781, 2002.

[362] M. G. Naffah-Mazzacoratti, G. A. A. Porcionatto, F. A. Scorza et al., "Selective alterations of glycosaminoglycans synthesis and proteoglycan expression in rat cortex and hippocampus in pilocarpine-induced epilepsy," Brain Research Bulletin, vol. 50, no. 4, pp. 229-239, 1999.

[363] E. Pollock, M. Everest, A. Brown, and M. O. Poulter, "Metalloproteinase inhibition prevents inhibitory synapse reorganization and seizure genesis," Neurobiology of Disease, vol. 70, pp. 21-31, 2014

[364] A. M. Arranz, K. L. Perkins, F. Irie et al., "Hyaluronan deficiency due to Has3 knock-out causes altered neuronal activity and seizures via reduction in brain extracellular space," The Journal of Neuroscience, vol. 34, no. 18, pp. 6164-6176, 2014.

[365] P. Yin, L. Yang, H. Y. Zhou, and R. P. Sun, "Matrix metalloproteinase- 9 may be a potential therapeutic target in epilepsy," Medical Hypotheses, vol. 76, no. 2, pp. 184-186, 2011.

[366] F. A. Konopacki, M. Rylski, E. Wilczek et al., "Synaptic localization of seizure-induced matrix metalloproteinase-9 mRNA," Neuroscience, vol. 150, no. 1, pp. 31-39, 2007.

[367] N. Suenaga, T. Ichiyama, M. Kubota, H. Isumi, J. Tohyama, and S. Furukawa, "Roles of matrix metalloproteinase-9 and tissue inhibitors of metalloproteinases 1 in acute encephalopathy following prolonged febrile seizures," Journal of the Neurological Sciences, vol. 266, no. 1-2, pp. 126-130, 2008.

[368] G. M. Wilczynski, F. A. Konopacki, E. Wilczek et al., "Important role of matrix metalloproteinase 9 in epileptogenesis," Journal of Cell Biology, vol. 180, no. 5, pp. 1021-1035, 2008.

[369] N. G. Cascella, D. J. Schretlen, and A. Sawa, "Schizophrenia and epilepsy: is there a shared susceptibility?" Neuroscience Research, vol. 63, no. 4, pp. 227-235, 2009.

[370] P. Gelisse, J.-C. Samuelian, and P. Genton, "Is schizophrenia a risk factor for epilepsy or acute symptomatic seizures?" Epilepsia, vol. 40, no. 11, pp. 1566-1571, 1999.

[371] M. F. Mendez, R. Grau, R. C. Doss, and J. L. Taylor, "Schizophrenia in epilepsy: seizure and psychosis variables," Neurology, vol. 43, no. 6, pp. 1073-1077, 1993.

[372] F. Lamprecht, "Epilepsy and schizophrenia: a neurochemical bridge," Journal of Neural Transmission, vol. 40, no. 2, pp. 159170, 1977.

[373] A. Brooks-Kayal, "Epilepsy and autism spectrum disorders: are there common developmental mechanisms?" Brain and Development, vol. 32, no. 9, pp. 731-738, 2010.

[374] R. Tuchman and I. Rapin, “Epilepsy in autism," Lancet Neurology, vol. 1, no. 6, pp. 352-358, 2002. 
[375] V. Wong, "Epilepsy in children with autistic spectrum disorder," Journal of Child Neurology, vol. 8, no. 4, pp. 316-322, 1993.

[376] R. F. Tuchman, I. Rapin, and S. Shinnar, "Autistic and dysphasic children. II: epilepsy," Pediatrics, vol. 88, no. 6, pp. 1219-1225, 1991.

[377] K. Jellinger, D. Armstrong, H. Y. Zoghbi, and A. K. Percy, "Neuropathology of Rett syndrome," Acta Neuropathologica, vol. 76, no. 2, pp. 142-158, 1988.

[378] E. Y. Deykin and B. MacMahon, "The incidence of seizures among children with autistic symptoms," American Journal of Psychiatry, vol. 136, no. 10, pp. 1310-1312, 1979. 

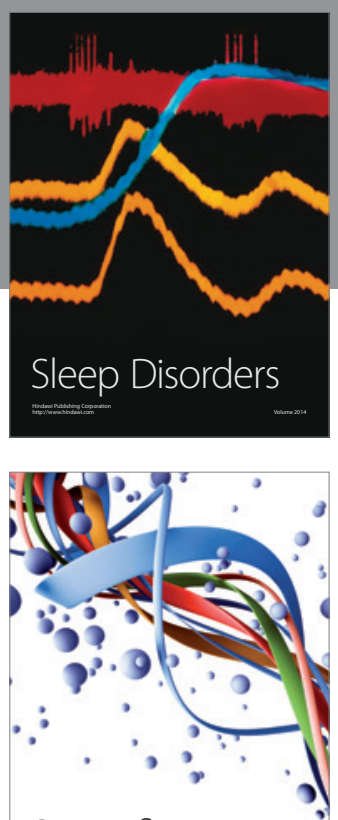

Scientifica
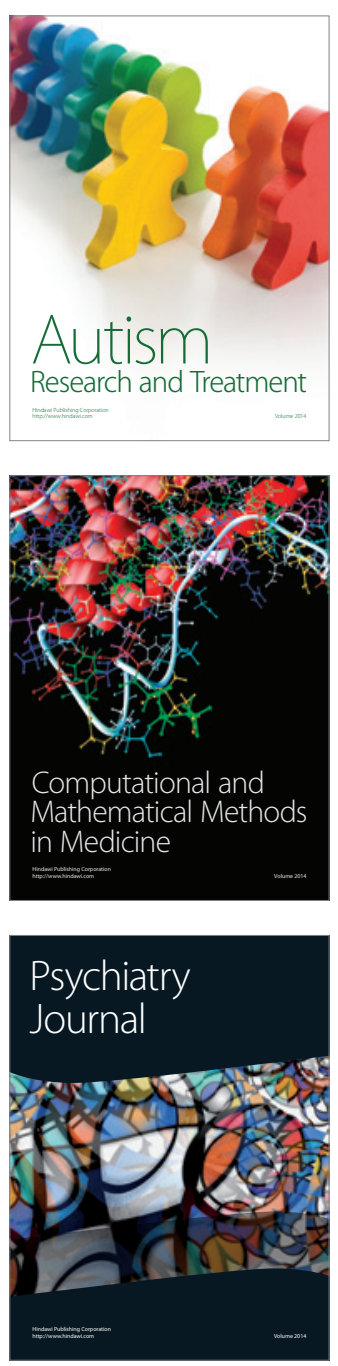
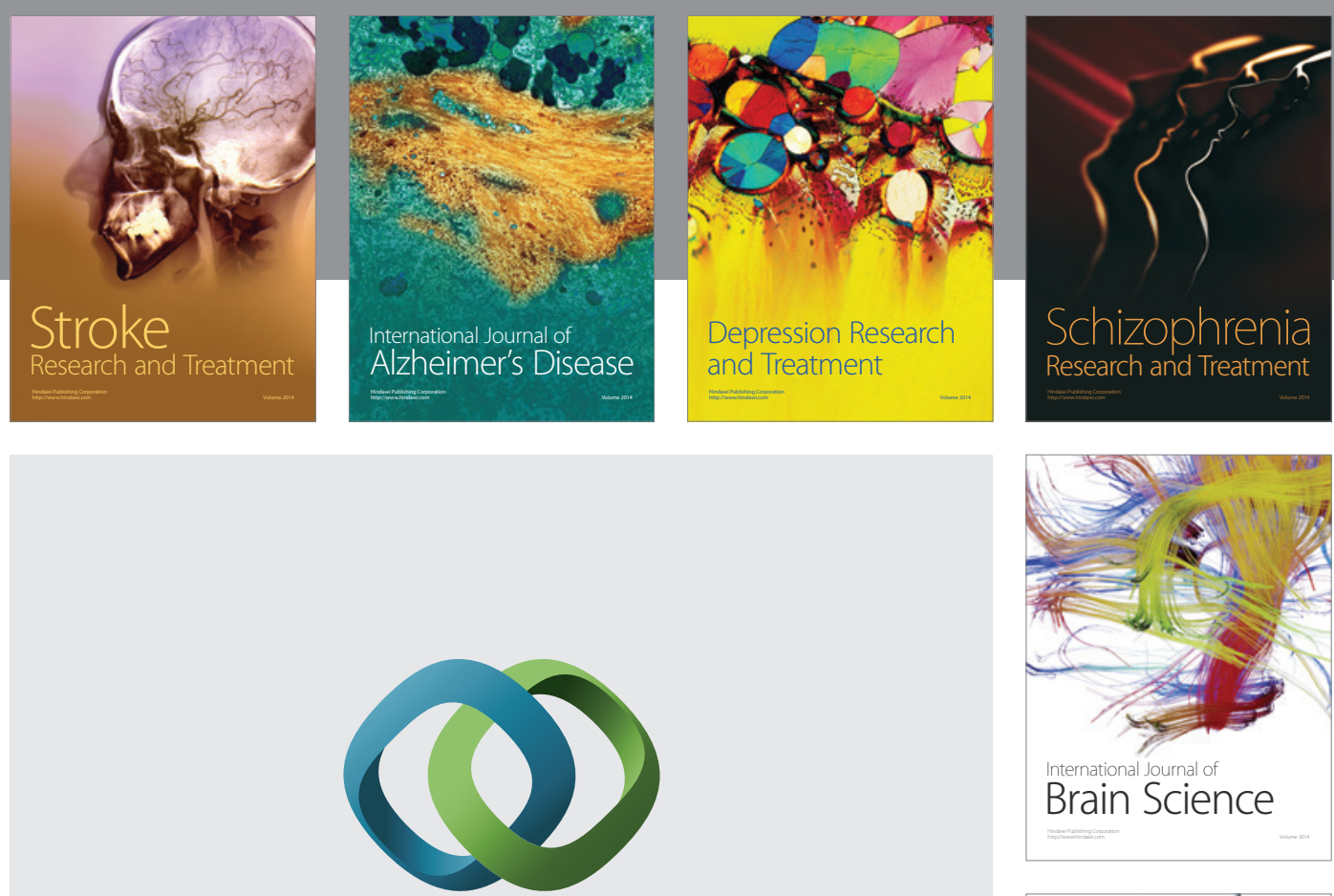

\section{Hindawi}

Submit your manuscripts at

http://www.hindawi.com
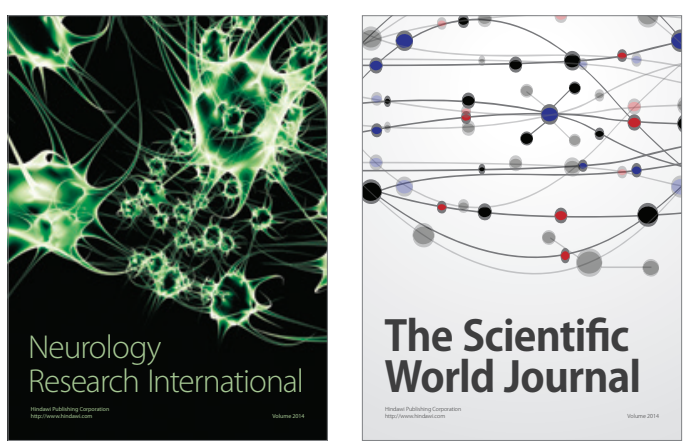

The Scientific World Journal

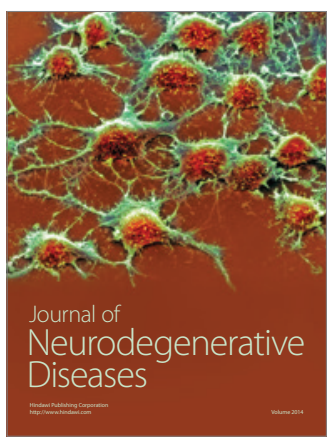

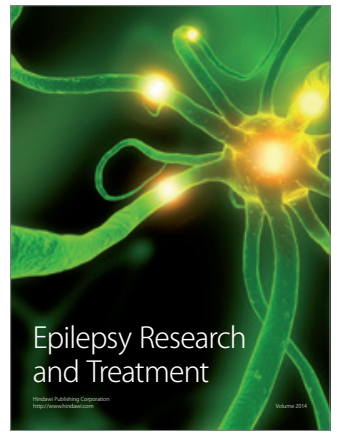

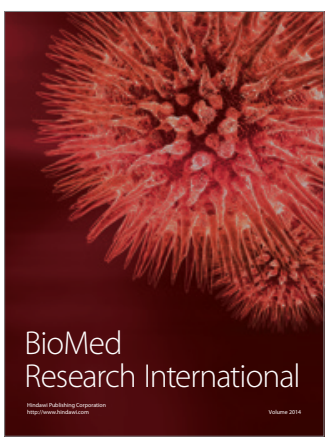

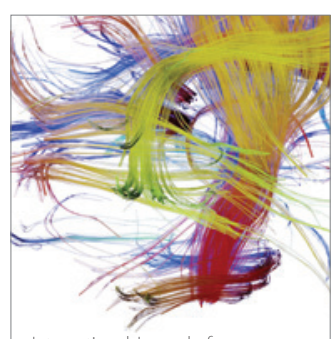

Brain Science

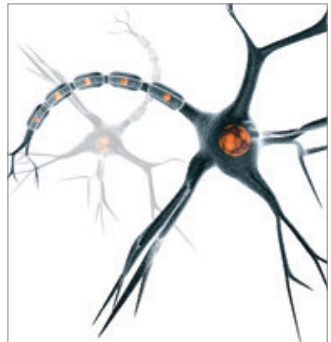

Neural Plasticity
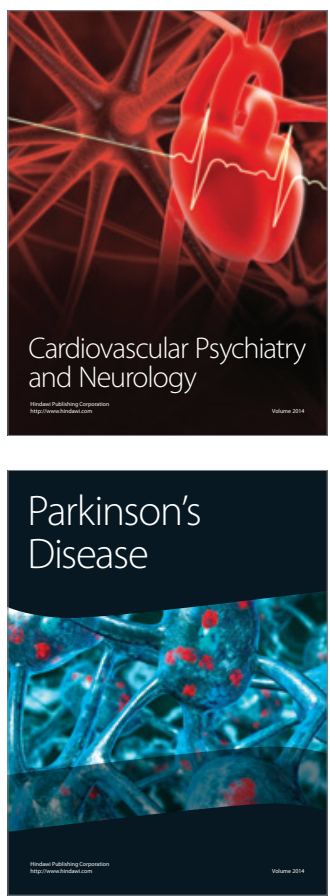